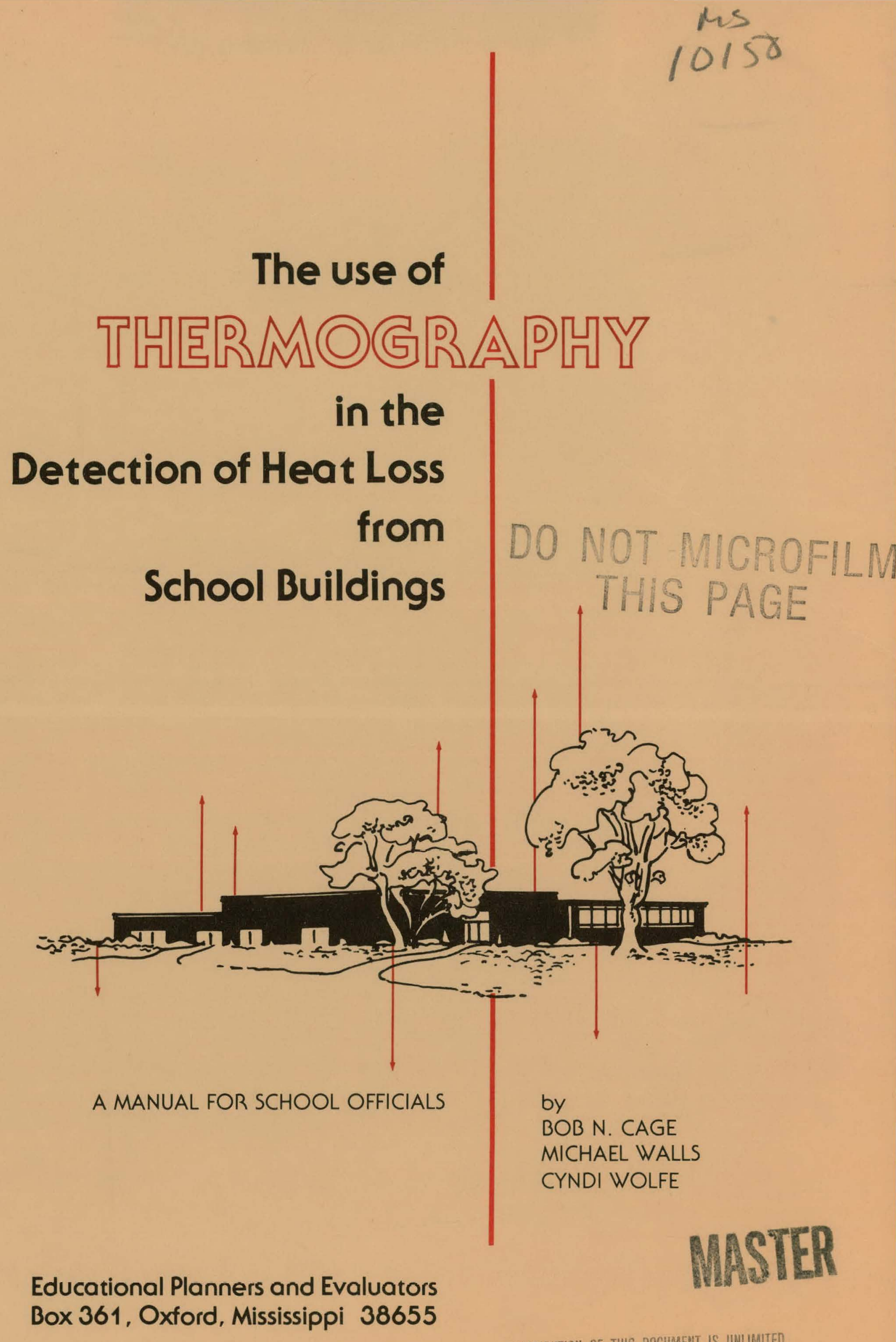




\section{DISCLAIMER}

This report was prepared as an account of work sponsored by an agency of the United States Government. Neither the United States Government nor any agency Thereof, nor any of their employees, makes any warranty, express or implied, or assumes any legal liability or responsibility for the accuracy, completeness, or usefulness of any information, apparatus, product, or process disclosed, or represents that its use would not infringe privately owned rights. Reference herein to any specific commercial product, process, or service by trade name, trademark, manufacturer, or otherwise does not necessarily constitute or imply its endorsement, recommendation, or favoring by the United States Government or any agency thereof. The views and opinions of authors expressed herein do not necessarily state or reflect those of the United States Government or any agency thereof. 


\section{DISCLAIMER}

Portions of this document may be illegible in electronic image products. Images are produced from the best available original document. 
$\mathrm{DOE} / \mathrm{R} 4 / 10150--\mathrm{Tl}$

DE84 000386

\title{
THE USE OF THERMOGRAPHY IN THE DETECTION OF HEAT LOSS FROM SCHOOL BUILDINGS:
}

\section{A Manual for School Officials}

\author{
by \\ Bob N. Cage \\ Michael Walls \\ Cyndi Wolfe
}

\section{Educational Planners and Evaluators \\ Box 361 \\ Oxford, Mississippi 38655}

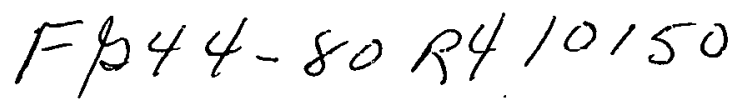

\section{DISCLAIMER}

This report was prepared as an account of work sponsored by an agency of the United States Government. Neither the United States Government nor any agency thereof, nor any of their employees, makes any warranty, express or implied, or assumes any legal liability or responsibility' for the accuracy, completeness, or usefulness of any information, apparatus, prnduct, or process disclosed, or represents that its use would not infringe privately owned rights. Reference herein to any specific commercial product, process, or service by trade name, trademark, manufacturer, or otherwise does not necessarily constitute or imply its endorsement, recommendation, or favoring by the United States Government or any agency thereof. The views and opinions of authors expressed herein do not necessarily state or reflect those of the United States Government or any agency thereof. 


\section{Table of Contents}

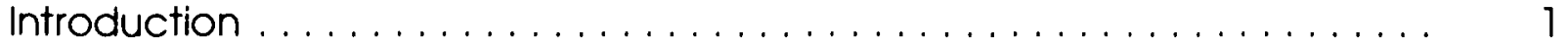

Approaches to the Assessment of Thermal Efficiency of a Building ....... I

Effectiveness of Systems . . . . . . . . . . . . . . . . . . . . . 5

The Use of Thermography $\ldots \ldots \ldots \ldots \ldots \ldots \ldots \ldots \ldots \ldots \ldots$

Cost-Effectiveness Considerations . . . . . . . . . . . . . . . . ........ 9

Use of This Technology in the Public School Setting $\ldots \ldots \ldots \ldots \ldots \ldots$

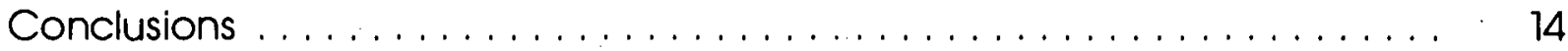

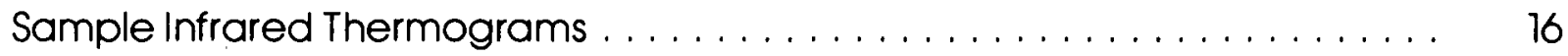

Annotated Bibliography. . . . . . . . . . . . . . . . . . . . . . 27 


\section{List of Tables}

Tables

Page

I. Cost to Purchase Representative System, 1980

5

II. Assessment of Costs to Utilize Infrared Technologies

9 


\section{List of Figures}

Figures Page

1. Spot or Infrared Thermometer ....................... 3

2. Thermal Line Scanner ............................ 3

3. Thermal Imager $\ldots \ldots \ldots \ldots \ldots \ldots \ldots \ldots \ldots \ldots \ldots \ldots \ldots \ldots$

4. Probeye Infrared Thermal Imager with Video Attachment ........ 4

5. Thermogram Showing Light and Dark Roof Areas. . . . . . . . . . . . 7 


\section{PREFACE}

This manual was the result of research funded by the U.S. Department of Energy, Appropriate Technology Program, Grant No. DE-FG448OR410150. The project, entitled "Evaluation of Energy Efficiency of Environmental Controls in Human-Use Structures." was conducted between March 1. 1980, and May 31. 1981. Although the application of the research is appropriate for all human-use structures, the major emphasis of the project was on school buildings.

Several agencies, both public and private contributed to the success of the project. A special thank you is extended to the Regional Planning Office. Research and Development Center, Jackson, Mississippi for their advice and assistance; to the EROS Applications Assistance Facility at the NASA/NSTL/Earth Resources Laboratory. Bay St. Louis, Mississippi for the loan of a Radiation Thermometer; to Mr. Steve Penix, Vanderbilt University for his photography and the production of the thermograms used in the manual; and to Mr. Michael Walls and Mrs. Cyndi Wolfe for their contribution to the research and to the writing of the manual.

The use of brand names in this manual does not represent endorsement by the Department of Energy or by the authors. The use of the Hughes Probeye by the technical consultant was to facilitate the research project and represents only one of several thermal imagers that could have been used.

Bob N. Cage, 1981 


\section{INTRODUCTION}

Inflation and the increasing cost of energy have caused school budgets to soar. Most school districts, however, have limited sources of income and the dollar squeeze is apparent. In inflationary times it is common to budget little or no funds for capital improvements and maintenance with the idea that other items in the budget are more important.

With fuel costs increasing dramatically compared to other budget items, it is becoming more important than ever to identify energy loss resulting from insufficient or inadequately installed insulation, loose fitting windows and doors, broken or leaking steam pipes, and other air leaks in roofs and walls. Heating and cooling costs can be reduced by adequately sealing air leaks in the building envelope. Wet insulation needs to be replaced; insufficient insulation needs to be increased.

To date, the identification and location of air leaks and the evaluation of insulation performance has been a difficult task. Now a new diagnostic tool called thermography gives promising results. Thermography is a combination of photography and infrared (IR) sensing. Infrared sensing permits direct measurement of apparent surface temperatures. Thermal information from an infrared sensor can be photographed with a $35 \mathrm{~mm}$ camera or a Polaroid camera, or recorded on video tape. With training, a person can interpret the thermograms and locate insulation voids and air leaks. This information provides useful guidance for retrofit decisions and evaluation of the quality and. effectiveness of corrective actions.'

Certain terms will occur throughout the following discussion. Without getting too deeply involved in definitional questions mord suited to the engineering or physics classroom, we must agree on what we mean by these terms. For purposes of this report, the following definitions will be used:

- Heat is the energy (of whatever kind) required to maintain a given temperature, or alternately to lower the temperature from one level to a lower level.

- Heat flow is the transfer of heat energy from one material to another, as from a radiator to the surrounding air. It has properties of direction, volume, and rate. Heat flow may be desirable or not, depending on the direction of flow; the differences in temperature involved, and on whether or not one must pay to produce the flow or to combat its effects. Insulation and other materials with high resistance to heat flow are used to block heat transfers, while heating element design and radiator panels are designed to speed the process.

0. Radiant heat is one of the types of heat flow in which heat is radiated into space. This form of energy is infrared radiation. Sunlight and heatlamps warm us in this manner. This is usually a minor element of heat flow from a structure, but it is important because it serves as a useful indicator for other, more serious forms of heat flow.

\section{APPROACHES TO THE ASSESSMENT OF THERMAL EFFICIENCY OF A BUILDING}

The various approaches to the assessment of energy losses in a building may generally be grouped into three categories. The simple procedures are usually performed as part of an "energy audit." Highly sophisticated assessment procedures may also be undertaken as an "engineering" or "architectural" study. In between these extremes of sophistication (and incidentally, of cost) lie the techniques revolving around remote sensing technology.

The energy audit is usually a combination of visual inspections of the structure and an analysis of energy usage patterns. Management practices may also be reviewed, as may blueprints or other technical documentation. The procedures usually take from a few hours to a few days, depending on the slze and complexity of the building. The results can be revealing in their effectiveness, but 
usually pinpoint only the most obvious waste. The recommendations from such a study might include reworking thermostats so that seldom-used portions of the building may be kept at a temperature closer to the exterior temperature than occupied areas, or increasing obviously inadequate insulation on exterior walls.

The energy audit is largely a systematic approach to "common sense" analysis. The building is comprehensively yet perfunctorily examined and the results compared to what could be expected from an ideal building of similar design. As a result, it points out major flaws in the structure and obvious inefficiencies in management practices. This is not to overly disparage the amount of good that can come from such a study, since it is axiomatic that the "obvious" seldom is until someone else points it out. However, the strengths of this approach are also its weaknesses, in that it only spots the obvious. For example, roof insulation may appear adequate to an auditor, but in reality large areas may be wet and therefore permit major heat losses.

On the other extreme lies the engineering study. In this approach, an engineer, architect, or other professional is hired to extensively test and analyze a structure. Sophisticated mathematical modeling of heat flow through exterior walls or of total heat budget is only one of the techniques utilized in such studies. The results of such studies are supplemented by intensive physical examination of the structure, possibly including most or all of the techniques mentioned in this manual.

Such studies usually result in suggestions for major capital investments, either in the heating and cooling (HVAC) plant or in the structural shell. As a result, such intensive studies are better suited to the new building before construction or to the older building about to undergo extensive renovation. However, the patron is assured that the building will be as energy efficient as is technically possible once the work is completed.

Most public structures, especially schools, have energy conservation needs that fall somewhere between these two approaches. Their operators feel that the high cost of energy in the building must be reduced in some way, even though the structure is fairly well-built. Obvious remedies will not make a large enough impact on costs, but it is questionable whether an expensive engineering study could result in enough savings to be cost-effective. The added question of potential extensive capital investment as opposed to higher energy bills must also be considered. The best approach in such situations is to supplement the basic energy audit with information obtained through thermal sensing.

The type of heat loss with which we are concerned primarily occurs through radiation. Radiated heat, or infrared radiation, however, is of two types for our purposes. A certain amount of radiation is emitted from an object because of its internal temperature. This, obviously, is the type of infrared radiation we would like to measure and is discussed in greater detail later in the manual. Such emitted radiation is, however, frequently masked by reflected radiation. This latter is the type captured by infrared photography, not thermal sensing.

Infrared photography uses total thermal radiation, both emitted and reflected, to affect the photographic emulsion on the camera film and produce an image. Unfortunately for our purposes, an object emits sufficient infrared radiation to be photographed without depending on reflected radiation from an outside source only when its temperature is above $250^{\circ} \mathrm{C}$. (or $482^{\circ} \mathrm{F}$ ). While this has limited utility in evaluating boilers or other heating and cooling machinery, it does not allow evaluation of the structure itself. $\left(250^{\circ} \mathrm{C}\right.$. is very near the temperature of a burning wooden building!) ${ }^{2}$

The use of infrared film is based not on the emission of infrared radiation by an object but on reflected radiation from an outside source, usually the sun. This is used for some gross measurements (as the military might use the technique to determine whether a given structure were in use or not), but the interpretation of such pictures requires some training. Educators might, however, consider such uses in the science curriculum, where accuracy would be secondary to qualitative results.

Thermal sensing is far more sensitive to the emitted radiation of objects at everyday temperatures. Because of this fact, thermal measurement or surveys can be conducted using several different types of instruments. A brief description of each type is given below, moving from lesser to greater sophistication required for its use and interpretation. 


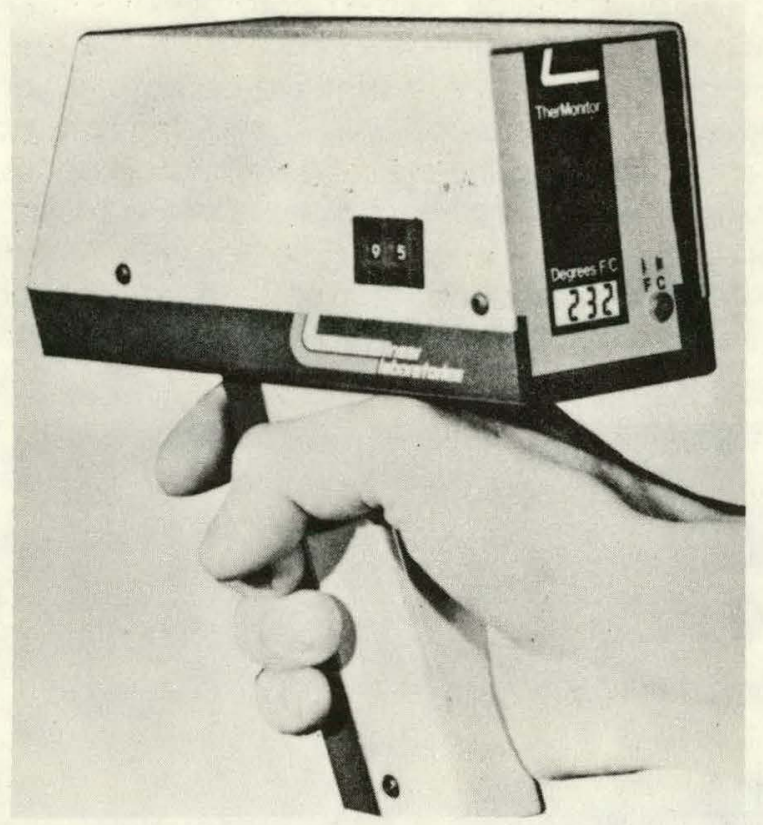

Figure 1. Spot or Infrared Thermometer

The simplest sensing device is the spot or infrared thermometer. (See Figure 1). It measures thermal radiation emanating from a spot or small area up to a distance of $2 \mathrm{O}$ feet away. A digital display readout or a simple meter reading indicates the temperature of the area. Thermometers of this type are sensitive to temperature ranges from $-40^{\circ}$ to $3100^{\circ} \mathrm{F}$. A recent adaptation is a telescopic lens that permits temperature measurement of $-20^{\circ}$ to $360^{\circ} \mathrm{F}$.

The thermal line scanner is also a hand-held instrument which measures along a scan line, that may extend across large areas of the structure to be evaluated. It can be used to measure infrared radiation emitted by all solid surfaces. (See Figure 2). Through a scanning mirror, the instrument

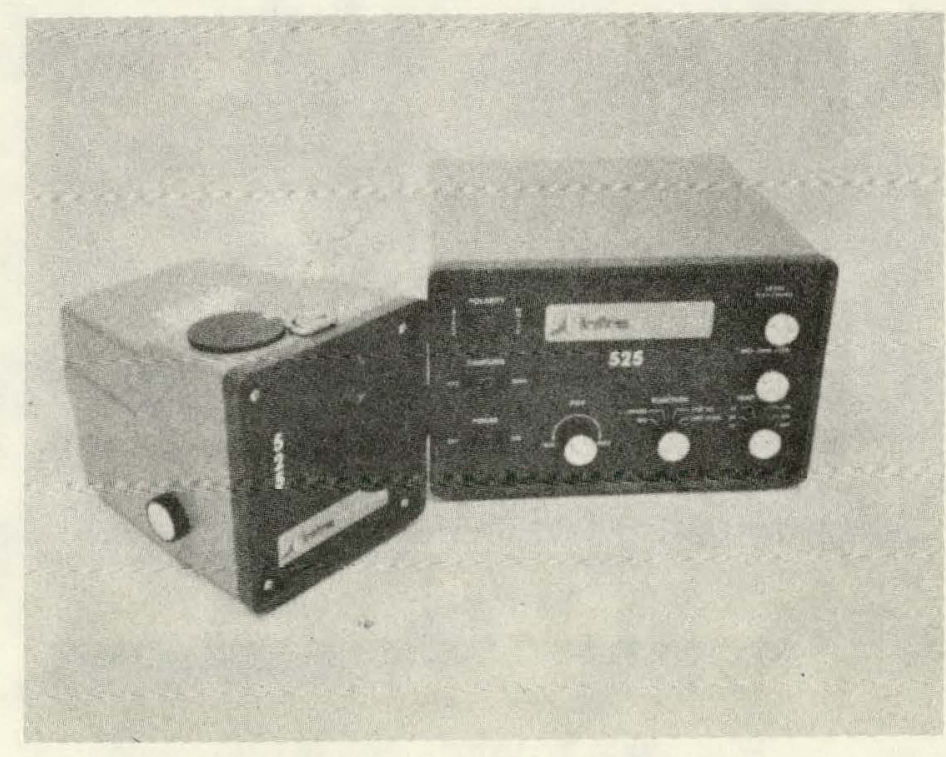

Figure 2. Thermal Line Scanner 
absorbs visible light, but reflects infrared energy. As the operator views the target scene, using visible radiation the instrument scans across the field of view and collects the infrared energy along a very narrow line. This collected energy is focused on a sensitive detector where it is converted into an electrical signal. The signal drives a display, usually a LED, showing a temperature variation profile along the scan line. The image with the scan line can also be photographed by attaching a Polaroid camera to the scanner, providing a permanent thermal profile of the image.

The next type of instrument is a thermal imager. (See Figure 3). A relatively small and complex system, it provides a complete two-dimensional thermal image (thermogram) of a scene. The components of the thermal imager are a power supply, a TV-type display unit, a scanner with a

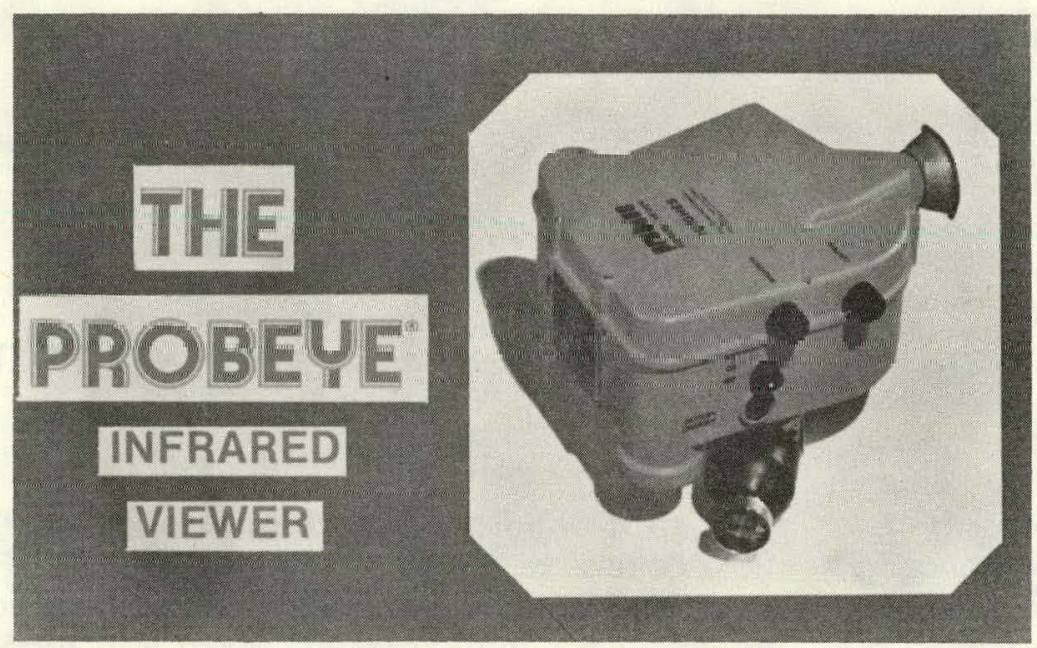

Figure 3. Thermal Imager

sensitive detector, and a camera or video system. (See Figure 4). The system may be ground-based or airborne. The thermogram details the relative heat pattern of the object scanned and an accompanying photograph from a $35 \mathrm{~mm}$ or Polaroid camera provides a two-dimensional picture in color or black and white. The distinction between the thermal imagers and the infrared line scanners lies in the number of dimensions along which the scanner operates. The imager produces a two-

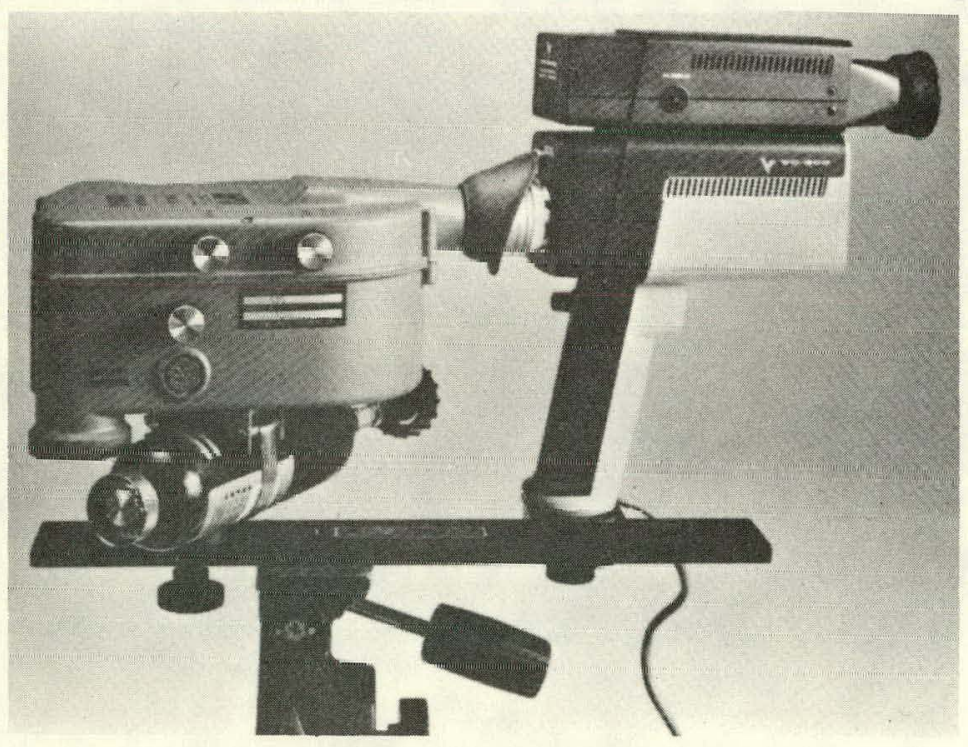

Figure 4. Probeye Infrared Thermal Imager with Video Attachment. 
dimensional image of the object being examined, while the line scanners produce a scan across a narrow band (effectively a one-dimensional image). The bands of the line scanners can, however, be used to build up a two-dimensional image in the same way the image on a television screen is produced.

Airborne thermograms can also be made by using a down-ward-looking infrared line scanner in an aircraft. As the aircraft moves in a horizontal, straight line, the scanner produces a one-dimensional, repetitive scan that, in combination with the forward motion of the aircraft, generates the data needed to produce a two-dimensional image of the thermal radiation detected from the ground level scene. ${ }^{3}$

The numerous infrared sensors now on the market may be broken down into several classes, based on the method of operation. Table I lists representative systems and their 1980 prices for comparison purposes. (Neither inclusion in or exclusion from this listing should be interpreted as a judgment concerning the desireability of any sensor on the part of the authors.)

Table I

Cost to Purchase Representative System, 1980

\begin{tabular}{|c|c|c|c|}
\hline Name & $\begin{array}{l}\text { Type of } \\
\text { System * }\end{array}$ & $\begin{array}{c}\text { Temperature } \\
\text { Range }\end{array}$ & Price \\
\hline Mikron 15 & ST & $-300 / 200^{\circ} \mathrm{C}$ & $\$ 1,025$ \\
\hline Mikron 22 & ST & $0 \% / 500^{\circ} \mathrm{C}$ & 885 \\
\hline Williamson 600 & ST & $400 / 1100^{\circ} \mathrm{C}$ & 850 \\
\hline Barnes ThermAtrace \| & LS & $N / A$ & 7,950 \\
\hline UTI Model $९ ० 0$ & LS & - $90^{\circ} \mathrm{C} .199^{\circ} \mathrm{C}$. & 43,000 \\
\hline \multicolumn{4}{|l|}{ Wahl Photo-scan } \\
\hline Infrared Thermometer & LS & $20 \% / 1000^{\circ} \mathrm{C}$. & 9,716 \\
\hline AGA Thermovision 110 & $\mathrm{TI}(\mathrm{hr})$ & $-30 \circ / 140^{\circ} \mathrm{C}$ & 12,800 \\
\hline AGA Thermovision 720 & $\mathrm{Tl}(\mathrm{hr})$ & $-200 / 200^{\circ} \mathrm{C}$ & 25,900 \\
\hline Daedalus DS-1230 & TI (hr) & $-100 / 40^{\circ} \mathrm{C}$ & 25,000 \\
\hline Probeye Model 650 & $\mathrm{TI}(\mathrm{Ir})$ & $0 \% / 100^{\circ} \mathrm{C}$ & 8,765 \\
\hline
\end{tabular}

SOURCE: Selected Manufacturer's Brochures

* ST-Spot or !nfrared Thermometer

LS-Line Scanner

II-Thermal Imager, high resolution (hr) or low resolution (Ir)

\section{EFFECTIVENESS OF SYSTEMS}

\section{Spot Infrared Thermometers}

The most common utilization of the spot infrared thermometer in analyzing energy efficiency of a structure is as a test of the thermal resistivity of a structural unit such as a wall. Thermal resistivity is the measure of the resistance to heat flow. The procedure used is to measure the internal air temperature, the interior surface temperature, and the exterior surface temperature. These values are then plugged in to an equation and resistivity calculated. The calculated resistivity can then be compared to the expected value for the structure, or multiple readings at various spots on the surface can be compared to locate variation across the structure.

The ease of use of this procedure, the low cost of its use, and the relatively low cost of purchasing the equipment all indicate that the use of spot infrared thermometers would require the least effort 
of any approach to the problem. However, effectiveness of the system must also be determined.

Unfortunately, according to research published by the National Bureau of Standards, "the technique utilizing hand-held infrared thermometers to determine the thermal resistance of walls... as recommended by the manufacturers of IRT devices appears to be considerably inaccurate under typical conditions for a residence." 4

Problems in system utilization included:

- Calibration problems of the device.

- Difficulties in determining the surface temperature at lower temperatures (especially below $0^{\circ} \mathrm{C}$ ), and

- Lack of control for convection and other transcient interference factors in the model on which resistance calculations are based.

Further, in the ideal case (in which everything works perfectly), the $0.5^{\circ} \mathrm{F}$ range of variation in measurement advertised by the manufacturers would create a 43 percent uncertainty factor in resistance calculations for an insulated wall, and 15 percent for an uninsulated wall. The added uncertainty of recorded temperatures tound during the evaluation would add a turther ' 23 percent uncertainty factor.

The study concludes that the devices can only be used qualitatively; that is, to determine whether or not insulation is present, or to discover gross flaws in the structure. "Measurements should be made under conditions which produce a 20 to $30^{\circ} \mathrm{F}$ temperature difference across the wall, and the coldside surface of the wall should be above $32^{\circ} \mathrm{F}\left(\mathrm{O}^{\circ} \mathrm{C}\right) .^{\prime \prime} 5$

\section{Thermal Imagers and Line Scanners}

Thermography using thermal imaging sensors has been widely used in recent years to evaluate thermal efficiency of buildings, locate potential faults in equipment, and note problems in industrial processes. The images produced by the sensor show patterns of light and dark areas (or in color imaging, a pattern of colors) with the shift in optical characteristics tied to intensity of temperature differentials. The user then relates these variations to characteristics of the structure known to have different thermal characteristics (i.e., solid walls as opposed to windows or doors). Once such differences in kind are accounted for, the interpretation revolves around locating reasons for otherwise unexplained anomalies.

The U.S. Army Cold Regions Research and Engineering Laboratory has tested the ability of selected thermal imaging systems to detect problem spots in laboratory settings by "building in" both gross and subtle flaws in test structures. Only portable units were used in these tests, making their results very useful for purposes of this study. (Unfortunately, however, this also severely limited the number of units available for testing.) The tests were conducted on four systems, including one line scanner and two thermal imagers listed in Table I, above. Two systems were classed as highresolution imagers, one as low-resolution, and the fourth was a line scanner.

The conclusions were as follows:

"The laboratory evaluation of various classes of infrared scanning equipment for the thermal inspection of buildings showed that the high resolution imaging systems performed better than both the low resolution imaging system and the line scanner. The high resolution systems correctly identified the known building defects in the test room with a certainty of $80 \%$ to $100 \%$ at the three test temperature differentials across the building envelope studied."

"The line scanner performed with a certainty of $25 \%$ to $60 \%$ and the lower resolution imaging system with a certainty of $20 \%$ to $60 \%$. The high resolution imaging systems 
and the line scanner showed little degradation in results as the temperature differential decreased. The low resolution imaging system did not perform well at the lowest temperature difference studied. All systems did better as a tool for detecting defects than as a tool for evaluating insulation levels in a structure."6

\section{THE USE OF THERMOGRAPHY}

Of all the systems aforementioned, thermal imagery or thermography is the most effective for use in individual school systems. Thermograms of buildings can be taken from the air or from the ground. Both airborne and ground systems use essentially the same type of infrared equipment. The final product is usually an image on film (a thermogram) which is a thermal image that bears a close resemblance to a photograph of a television image.

The airborne system differs mainly from the ground system in that the scan image is built-up lineby-line by the forward motion of the aircraft. As with a television image, building details are recognizable by their shapes and sizes. Unlike television, which uses visible light radiation reflected from the surface of objects to create an image, infrared scanners use invisible heat radiation emitted by the surfaces of objects to create an image. Because emitted radiation is detected, infrared scanners can be used day or night.

Infrared thermal imaging systems operate in either the midwave infrared (2 to $5.6-u$ ) wavelength or longwave infrared ( 8 to $14-u$ ) wavelength portions of the infrared spectrum. These two spectral bands are "windows" through which infrared radiation can pass without being absorbed by the atmosphere. In a thermogram, shades of grey or color-tone variations represent the amount of thermal energy radiating from each element of the scene. Warmer areas of the thermal image are lighter and cooler areas are darker. (See Figure 5). Thermograms in color show cooler areas tending toward the blue color ranges and warmer areas tending toward the red color ranges. For most building components, the tones of various surfaces are approximately proportional to their temperatures.

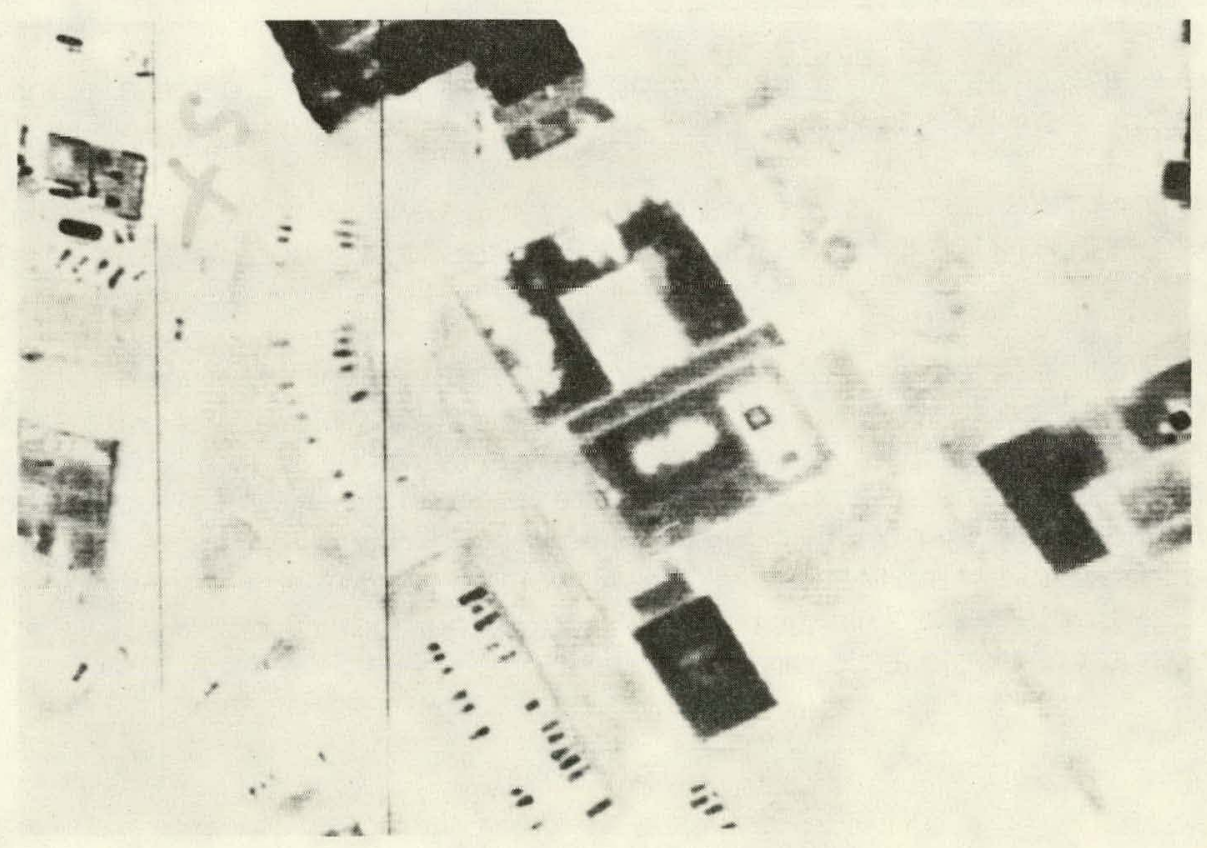

Figure 5. Thermogram Showing Light and Dark Roof Areas 
Unpainted metal surfaces are the major exception to this rule. Bright metal roofs or flashing will usually be relatively dark (often black) on thermograms even though they may be no colder than surfaces showing lighter tones. For this reason, thermograms are said to represent "apparent" rather than actual surface temperatures.

Airborne systems are best for investigating the roofs of all types of buildings if the cost of the survey can be shared by a large number of schools. Helicopters are the ideal platforms for airborne systems when high resolution is necessary to bring out roof detail, especially on large, low, flat roofs. Fixed-wing aircraft are best for higher altitude coverage of larger urban areas with several schools.

The much cheaper ground imaging systems are best for investigating the roofs of a small number of buildings, the interior and exterior walis of any building, and other interior features, such as steam traps. Ground systems used in cherry pickers can effectively scan the roofs of buildings up to fifty feet high.

The maximum temperature gradient should exist between the inside and outside surfaces for any investigation. For general purposes, cold winter nights or cold overcast winter days are recommended. Water-damaged roof insulation can also be detected on hot, clear summer afternoons.

Actual surface temperatures, and therefore estimations of conductive heat loss, cannot be determined by infrared methods, but must be determined by contact methods. However, infrared methods can quickly identify those areas on the surtace of a given building uppearing to have excessive conductive heat loss.

The technique has limited usefulness in prioritizing conservation targets within a given building or among different buildings because heat may be lost by conduction through surfaces hidden to view and because other types of heat and energy losses (air exfiltration, etc.) may be much greater than heat loss by conduction.

The technique is effective when used alone in certian specific situations, and may be effective when used where necessary in combination with other techniques to analyze the energy budget of a given building. Infrared techniques are most effective in those situations where conductive heat losses are:

a. Suspected to be relatively large, but where existing records or a simple (often visual) inspection cannot find the exact areas of heat loss;

b. where the expense of a survey can be distributed over a large number of suspect buildings or surfaces; and

c. where corrective measures are relatively inexpensive compared to the value of the energy saved. (This assumes, of course, that recommended corrective measures will be taken.)

The existing infrared technology is being used in both the public and private sectors for heat loss surveys. It appears to be used more extensively in the private sector because investigations are generally limited to those situations discussed above.

For maximum effectiveness, thermography surveys should be carried out on a regular schedule vecause the situations to which they ure best adapted gre nften those requiring continuous attention and/or periodic maintenance. These would include water-damaged insulation and defective steam traps. The administrator with a large number of older buildings under his/her jurisdiction may find it feasable to obtain use of such equipment. 


\section{COST-EFFECTIVENESS CONSIDERATIONS}

Cost-benefit analyses, of whatever type, require three types of input:

- Cost data, both direct and indirect, of the option under consideration:

- Data on improvements in the subject; and

- Some methodology for correlating treatment to the observed changes in the subject.

For our purposes, the first and third type of data is readily available. For the second, however, there is not available any comparable average improvement figures from which to assess the effectiveness of any improvements that might be required in a school plant. Because of this weakness, the following discussion is necessarily generalized. Still, some assessment of cost-effectiveness is possible, if one takes available estimates of costs and savings as suitably precise for such calculations.

Table Il, below, gives a summary of costs for each type of system. These figures will be used as a starting point of the analyses to follow.

\section{Table II \\ Assessment of Costs to Utilize Infrared Technologies}

\begin{tabular}{|c|c|c|c|}
\hline \multirow{2}{*}{$\begin{array}{l}\text { Criterion } \\
\text { of Cost }\end{array}$} & \multicolumn{3}{|c|}{ Type of System } \\
\hline & $\begin{array}{c}\text { Spot } \\
\text { Thermometer }\end{array}$ & $\begin{array}{l}\text { Line } \\
\text { Scanner }\end{array}$ & $\begin{array}{l}\text { Thermal } \\
\text { Imager }\end{array}$ \\
\hline Average Cost & $\$ 920$ & $\begin{array}{l}\$ 8,250- \\
42,000\end{array}$ & $\begin{array}{l}\$ 10,750- \\
25,000\end{array}$ \\
\hline Number of Uses' & $10-120$ & 10 & 10 \\
\hline Average Lease 2 & N/A & S 300 & S 300 \\
\hline Effectiveness & low & moderate & high \\
\hline
\end{tabular}

'Based on average expected 10 years life cycle.

2Lease costs are for system only; consultant costs, materials, interpretation, and other costs are not included.

As stated earlier, infrared thermography of buildings is a rapid, non-contact, realtime technique that uses an infrared thermal imaging system to detect heat loss or gain, structural defects, moisture. and other anomalies in building envelopes. For general surveys of schools and other public buildings, thermograms produced by the thermal imager system are the most effective system available at present. Therefore, no evaluation of less effective systems will be attempted. This is especially so since no quantitative data exists whereby the cost per percentage of accuracy can be assessed. In the absence of such data, no comparisons can be made between systems of markedly different effectiveness in detecting problems.

Ground-based thermography systems are simple to operate, and can be used by one competent person after a brief training period. The resulting thermogram is relatively easy to interpret by either a knowledgeable technician or the operator. The minimum investrient in such a 
system would be around $\$ 10,000$ excluding the van or other transportation on which it would be mounted.

Such a ground-based survey would cost between $\$ 100$ and $\$ 500$ for a half-day lease (enough time to examine the average school plant). Airborne systems are normally priced out of reach for smaller agencies, and even the costs of contracting such a survey is quite high. This is due to the costs of flying time and professional analysis, as well as the higher costs of the system. Reports and miscellaneous data (including ground-truth data to compliment the airborne data) should be added to these costs. The total expenditure is therefore hard to estimate. For our analysis, we estimate the costs of such a survey at $\$ 2000$ for a day's coverage of numerous structures.

Total costs for a heat loss survey, therefore, could reasonably be expected to be as low as $\$ 300$ per structure for buildings comparable in size to schools with 600-900 students. This figure assumes that three buildings can be evaluated per night using ground-based equipment, or that a minimum of twenty structures can be evaluated from the air. (The $\$ 300$ figure includes collection of groundtruth temperatures on building roofs and walls to calibrate the imagery and to aid in estimating emissivity, as well as the costs of the equipment lease.) Image enhancement, interpretation, and analysis can add a further $\$ 100$ to $\$ 200$ per structure when necessary for analysis, as is usually the case with airborne surveys.

Costs are fairly easy to estimate, working with quoted costs for similar work provided by commercial tirms, or trom suppllers' prlce lls is. Expecled ben iefils cire niure diffieult to estimatc with the limited experience published thus far. The only reliable data available for situations involving energy losses that would otherwise have been difficult to detect or at sites difficult to detect without thermography are for water-damaged insulation under flat, built-up roofs and for defective steamtraps within buildings. In such situations, other methods would be prohibitively expensive due to the required manpower or because of the often destructive nature of the physical search. Unfortunately, most of the reports published by researchers justify the use of thermography (and other forms of remote sensing) based on examples where the nature and location of the problem was previously known, or suspected with a high degree of confidence. (For example, losses through single-pane windows.) Other examples are given where energy losses are detected that would be impractical to EüPeEt.

The return (benefits) to a school district for aerial surveys of large, flat-roofed buildings seems to be on the order of ten dollars on fuel savings over a two or three year period for every dollar spent on the survey, but not including the cost of repairs. For major repairs, such as a complete reroofing, estimates of annual fuel savings are from $8 \%$ to $10 \%$ of the total cost of the survey and repairs. (Bear in mind that these figures are only estimates from a select group of structures where the owners had suspected insulation defects due to abnormally high fuel costs.) No follow-up data are available on actual fuel savings.

The major returns when using ground surveys seem most likely to come from the detection of faulty electrical-mechanical equipment and steam traps. The returns in fuel savings appear to average about $\$ 1,000$ per year per bullding if a large number (thirty or more) of buildings are surveyed. As with the aerial survey, this amounts to an average return of three fo four dollars for the first year per dollar spent on the survey, but again not including the costs of repairs. Savings may not accumulate beyond the first year or two because steam traps easily become defective, and should be re- examined periodically.

We may assess the cost-effectiveness of these systems using the general cost flgures glven above. The procedure chosen for this assessment is called life-cycle costing. In this approach, designed for assessing capital irvestments, the costs and the benefits of a decision are calculated over the lifetime of the capital item. To simplify the many Intangibles involved, we shall assume an effective lifetime of 10 years for the equipment, with no maintenance or repair costs and no amortization. (The simplifying assumption is that the effective life beyond the conservative 10-year estimate will offset maintenance costs of the system.)

First, let us examine the cost-effectiveness of buying a less-expensive. low-resolution thermal imaging system. 


$$
\text { COST }=\frac{\text { purchase price }}{\text { life-expectancy }}=\frac{\$ 10,725}{10 \mathrm{Yrs} .}=\$ 1,072.50 / \mathrm{yr} \text {. }
$$

BENEFIT $=\$ 1000 /$ building/yr. after the first use. Based on these figures, a single annual use would produce an average annual net cost of $\$ 72.50$ for one building; or $\$ 725$ for the life cycle of the equipment. (This assessment assumes that the equipment is used only often enough to maintain the average benefit of $\$ 1,000$ /year over the life of the system, assumed to be once annually.) However, if a second building is evaluated as well, the system will produce a net benefit of $\$ 927.50$, or enough to pay for the system in slightly over five years from purchase.

Alternatively, let us examine the cost-effectiveness of leasing the system.

$$
\begin{aligned}
\text { COST } & =\text { lease price/use } \times 1 \text { use } / y r . \times 10 \text { years } \\
& =\$ 300 / \text { use } \times 10 \text { uses, or } \$ 3,000 .
\end{aligned}
$$

BENEFIT $=\$ 1000 /$ building/yr. (after the first year). Based on these figures, a single annual use would produce a net annual benefit of $\$ 700$, or $\$ 7000$ over the time period equivalent to the life cycle of a system. However, the net benefit per use would remain constant if a second building were to be evaluated, since the lease cost per unit would be constant.

It is obvious from these calculations that the small user would be much better off leasing the system once a year and avoiding the major capital investment of purchasing, as well as the personnel and other associated costs for in-house operation. However, if two or more buildings are to be evaluated annually, the purchase of such a system would be advisable. (At two building units per year, the net benefit for purchase is $\$ 1,463.75$ versus $\$ 1,400$ for leasing. This occurs since unit costs are constant for leasing, while total costs are constant for purchase.) Similar calculations may also be made for other combinations of systems, but without better information as to the impact upon energy savings, the exercise would not be fruitful.

In summary, the use of thermography is projected to be cost-effective, based on the number of structures to be tested and the ability of the agency to make the capital investment involved in pursuing the most cost efficient approach.

\section{USE OF THIS TECHNOLOGY IN THE.PUBLIC SCHOOL SETTING}

The following outline summarizes a set of criteria which, when met in a given situation, should determine the appropriateness of using thermal remote sensing technology. Each criterion should be carefully and honestly considered by the prospective user, and the problems and advantages carefully weighed. Remote sensing cannot be simply considered a "Technological fix", or the user will waste scarce resources without concomitant gains.

I. Needs Assessment, or "What's the Problem Here?"

A. Energy-conserving activities are needed when:

1) One building costs far more to operate than comparable structures within the system, or

2) Energy utilization has increased dramatically, or

3) One part of a building is significantly colder or hotter than the rest, or costs more to maintain at a comparable temperature. 
B. Conservation activities are only worth pursuing if funds are available for repairs to buildings, and the financial situation and/or status of the structure does not call for replacement.

C. Expensive outside consultants and/or technologies are not needed until all common-sense remedies have been considered.

II. Choosing Alternative Technologies, or "Which Approach is Best?"

A. Do a preliminary inspection first. Note any obvious problems. If you can stand in front of a closed window and feel a draft, you don't need to spend $\$ 10,000$ to find out your problem.

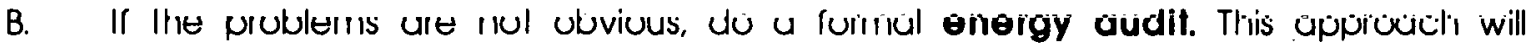
systematize common sense and make sure no areas were overlooked in your first revlew. A well-done energy dudil finds roum for innovement in even the musl energy-efficient structure, but in some cases the results may be too generalized for your purposes. Fo'r example, the audit may note excessive heat loss through the roof, but noof fell you whefher to dada insulation, check the condition of the existing insulation or look for leaks.

C. If the results of the audit are not sufficient guidance for programming renovation activity, then use the thermal imager technology. (Our specific recommendations are contained in the Summary, and the reasons elsewhere in the text.) The results of this study should, in conjunction with your audit results, give you enough information to determine the best use of your renovation funds and to largely guide your workers to the source of the problem condition.

III. "Do I Lease the System or Should I Buy It?"

A. Lease the system if:

1) You have a small number of buildings.

2) You have limited capital funds for equipment, or would have to divert renovation funds into the acquisition of the equipment to tell you where to use your renovation funds,

3) The building is approaching the end of its usefulness,

4) You don't have adequate funds for follow-up minor repair and the maintenance required to get the full benefit from frequent use of the system is too great.

B. Buy the system if:

1) You have more than a few buildings,

2) You can afford the capital outlay of purchase without short-changing other activities,

3) The buildings in question are relatively new. 
4) You have enough funds to handle reasonable follow-up on the results of frequent utilization of the system.

IV. "Do I Hire a Consultant?"

A. Hire a consultant if:

1) You do not want to buy the equipment. (Leasing the system would probably cost you excessively since your staff would need reasonable training time on the system. However, after a few times with the work done by others, your staff should be able to give reasonable production on a leased system.)

2) You are highly understaffed, or feel your personnel not suitable for a technical task such as this. (Be honest-a good system with operators out of their depth is worse than useless.)

3) Your staff lacks the architectural and/or engineering background to be able to intelligently use the system or interpret the results.

4) You are for whatever reason under time pressure.

B. Do the work in-house if:

1) You intend to buy the system.

2) Your staff knows the structure and physical plant of the target building well enough to intelligently use the system and interpret the results.

3) Your staff is large enough to allow special assignment of a small team to this task without handicapping other activities.

V. Sequence of Events for Use-

A. Acquire system and training if appropriate.

B. Conduct energy audit.

C. Doscan with ground truth Information as needed.

D. Interpret results. (This is the key to the whole process. Use every bit of available data to do the interpretation. Develop alternative hypotheses to explain the results: subsequent steps will eliminate those that are incorrect. Be especially sure to use the results of previous studies to guide your efforts.)

[. Use blueprints and similar data to determine structural causes of problems shown by scan.

F. Trace the problem to its root. For example, replacing wet insulation is worthless if you don't fix the leak.

G. Estimate the costs of each repair versus possible savings. (This may be hard at first, but as you gain experience, cost information in your files will guide you.) 
H. Calculate the best mix of repairs that your budget will allow. Keep.a list of others for when funds or staff time may become available later.

I. Make the repairs.

J. Do a follow-up scan, if at all possible. (This has two purposes-to see if the repair worked, and to give better training in interpretation using pre- and post-treatment material.)

K. Keep good cost records to let you refine estimates of benefits for the next time.

\section{CONCLUSIONS}

There exist a number of remote sensing technologies that will allow the user to determine temperature variations within a structure. Many of these may be considered "off-the-shelf" technologies, that an unsophisticated user may purchase and utilize. However, for our purposes, the thermal imager systems give the best information for the cost. Of these systems, the low-resolution imagers, as typified by the Hughes Probeye, are most suitable.

The results of a scan using such a device is presented as an image on the viewing screen analagous to the image on a television. This may be interpreted directly from the viewer, but it is far more efficient to record the image photographically. A polarold-type camera may be used, as may a $35 \mathrm{~mm}$ or even a video camera. We recommend the use of a good-quality $35 \mathrm{~mm}$ single-lens reflex (SLR) camera without the recently introduced automatic focusing features. (The SLR camera's viewfinder lets the user look through the lens at the target rather than through a separate prism. In this instance, that is the only way to see the viewscreen of the thermal imager.) For best results with the Probeye, a $50 \mathrm{~mm}$ lens should be used with 400 ASA film at 1.4 and a shutter speed of $1 / 30$ th of a second. Other systems may require different configurations, but the dealer should give you the needed specifications at the time of sale or lease.

It should be noted that a polaroid-type camera may not be used if the scan is conducted from a moving vehicle. Such cameras usually have a minimum shutter speed of 4 seconds, which will cause substantial blurring of the photograph.

When the camera is mounted on the system, the viewer must be focused first. The camera is then focused on the image on the screen, and the optimum setting used. Once this camera setting is completed. DO NOT refocus the camera. Any needed adjustments should be made on the imager instead. 


\section{List of References}

1. Infrared - An Energy Tool. New Infrared Techniques can Pinpoint Sources of Building Heat Loss. U.S. Department of Energy, Washington, D.C., 1980.

2. Personal communication to the senior author from Sheldon Phillips, Customer Technical Service Representative, Eastman Kodak Company, April 11, 1980.

3. Marshall, Stephen J. Infrared Thermography of Buildings - A Bibliography with Abstracts. U.S. Army Cold Regions Research and Engineering Laboratory, Hanover, New Hampshire, 1979.

4. Trendo, Stephen J. and Douglas M. Bunch. Evaluation of Hand-Held Infrared Thermometers for Wall Thermal Resistance Determinations (NBSIR 79-1736). U.S. Department of Commerce, National Bureau of Standards, July, 1979. pp. 18-19.

5. Ibid. p. 19.

6. Grot, Richard A., Richard H. Munis, Steve J. Marshall, and Allen Greatorex. A Comparative Testing of the Applicability of Various Thermal Scanning Systems for Detecting Heat Losses in Buildings. In Proceedings of the Fourth Biennial Infrared Information Exchange, August 22-24, 1978. pp. 1394-1395.

7. Infrared - An Energy Tool. p. 3. 
The following section of this report provides examples of common causes of heat loss which have been detected through the use of infrared thermography. The SAMPLE pictures are in black and white for purposes of this report as black and white INFRARED THERMOGRAMS photographs reproduce more clearly. In black and white photos, the lighter the shade, the hotter the apparent surface. Thus black indicates a cooler apparent surface temperature, and bright white indicates a hot apparent surface temperature.

When color film is used, shades of red indicate the level of heat being emitted from the surface. The darker or more intense the shade of red, the hotter the surface.

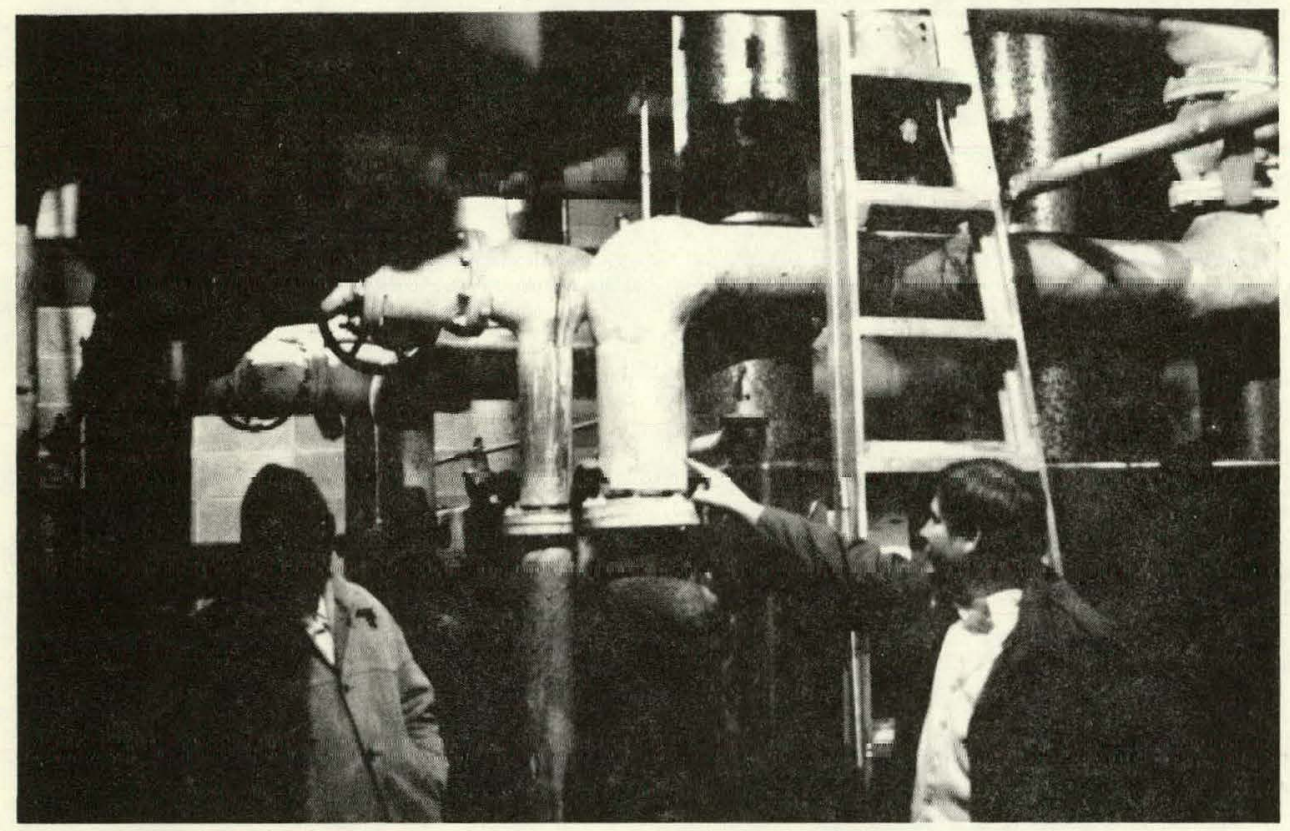

Photograph 1

shows an insulated steam pipe (on the right) with an uninsulated pipe on the left.

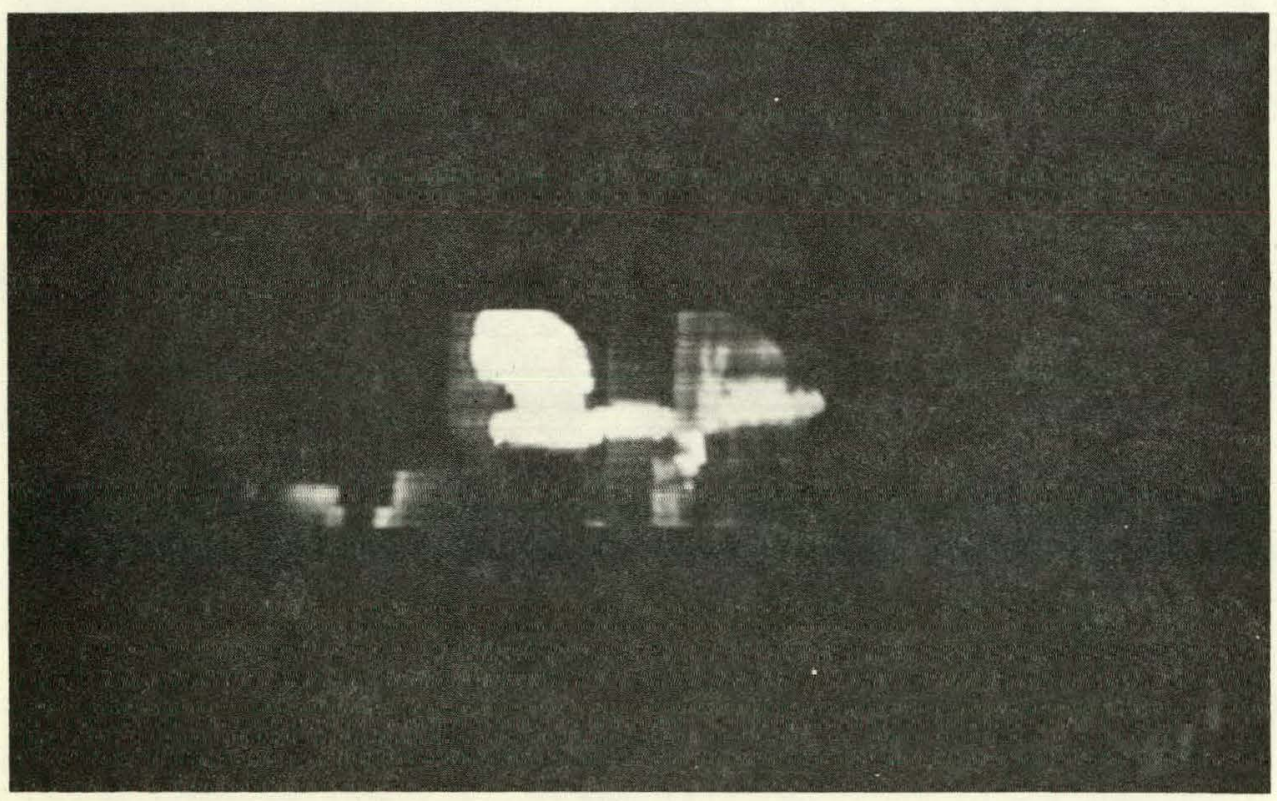

Thermogram 1

shows the same pipes.

Note thot the Iminsilloted pipe is bright white, indicating a high surface temperature and apparent heat loss. 


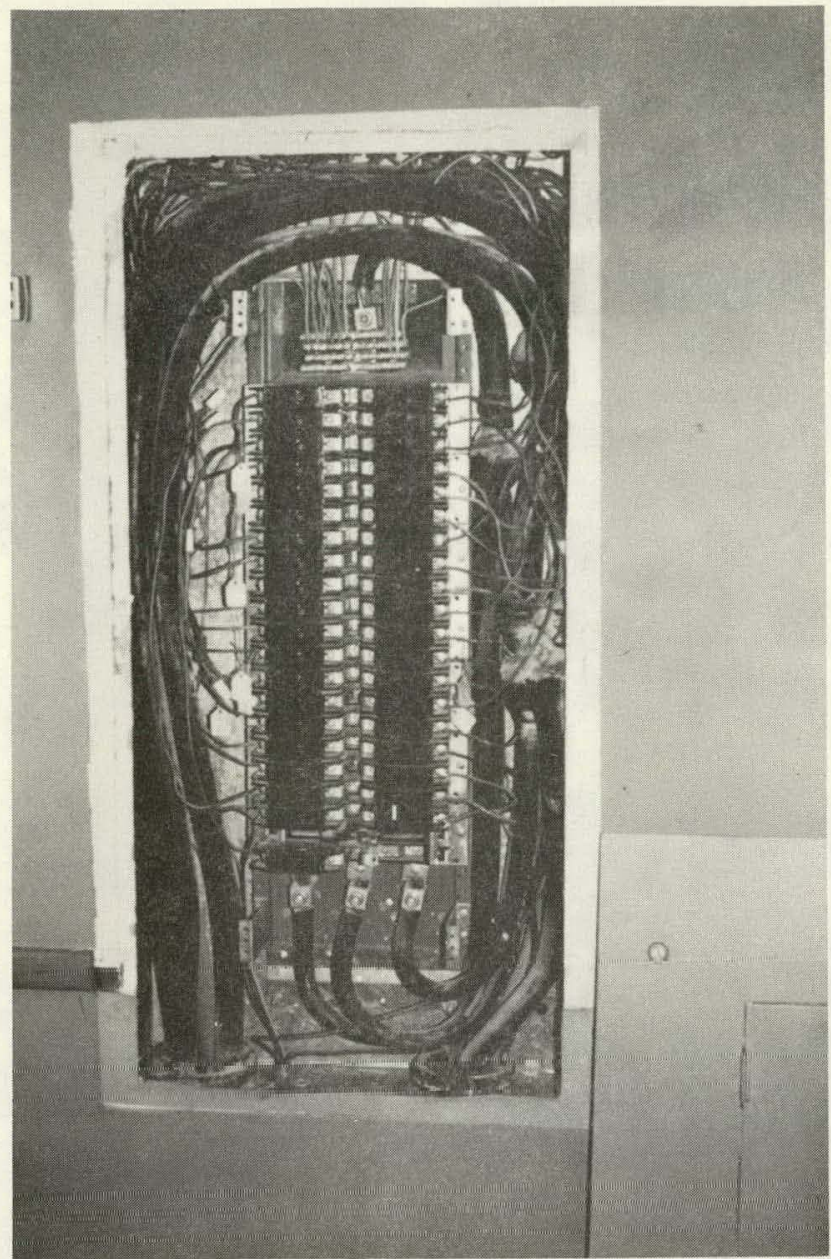

\section{DETECTING OVERHEATED ELECTRICAL CIRCUITS}

Photograph 2

shows a circuit box for the electrical system of a school system

Thermogram 2

reveals several overheated circuits which are potential fire hazords.

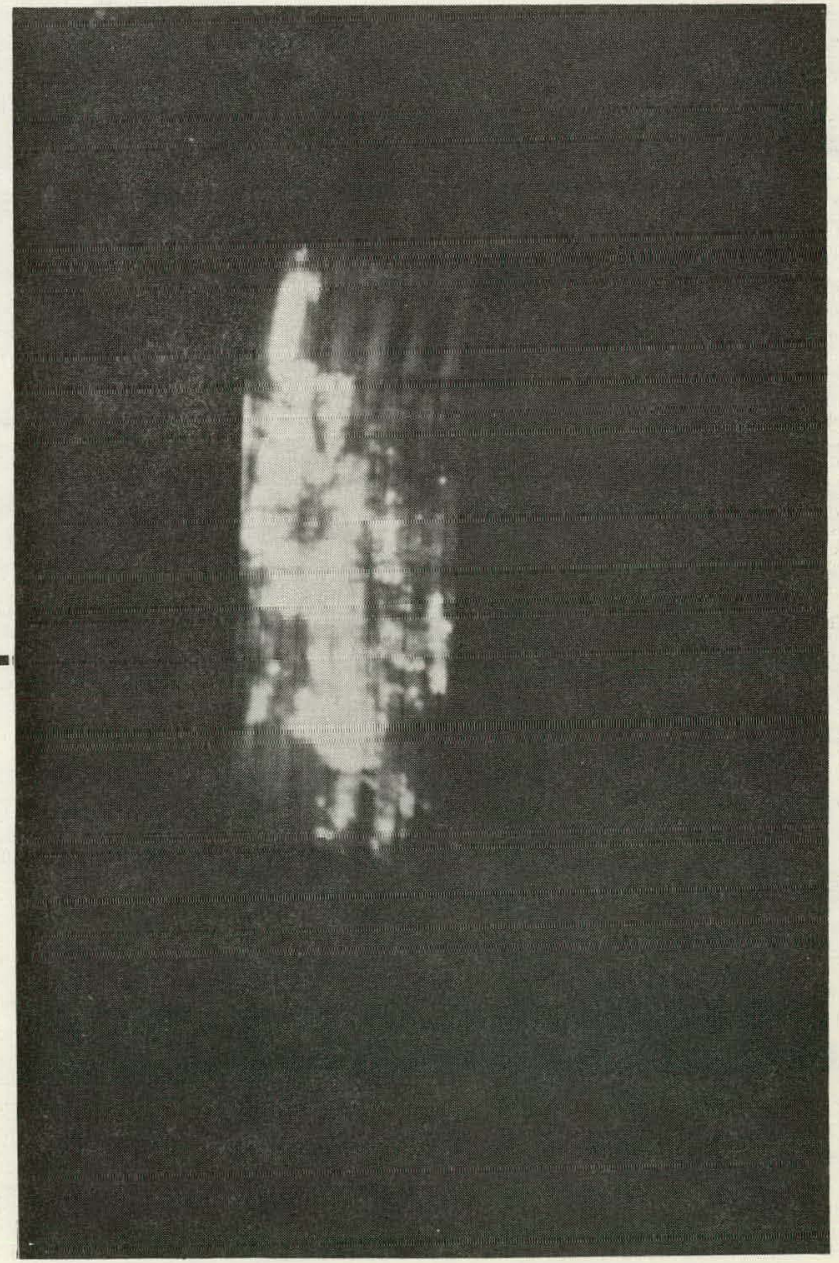




\section{DETECTING UNBALANCED ELECTRICAL PHASING}

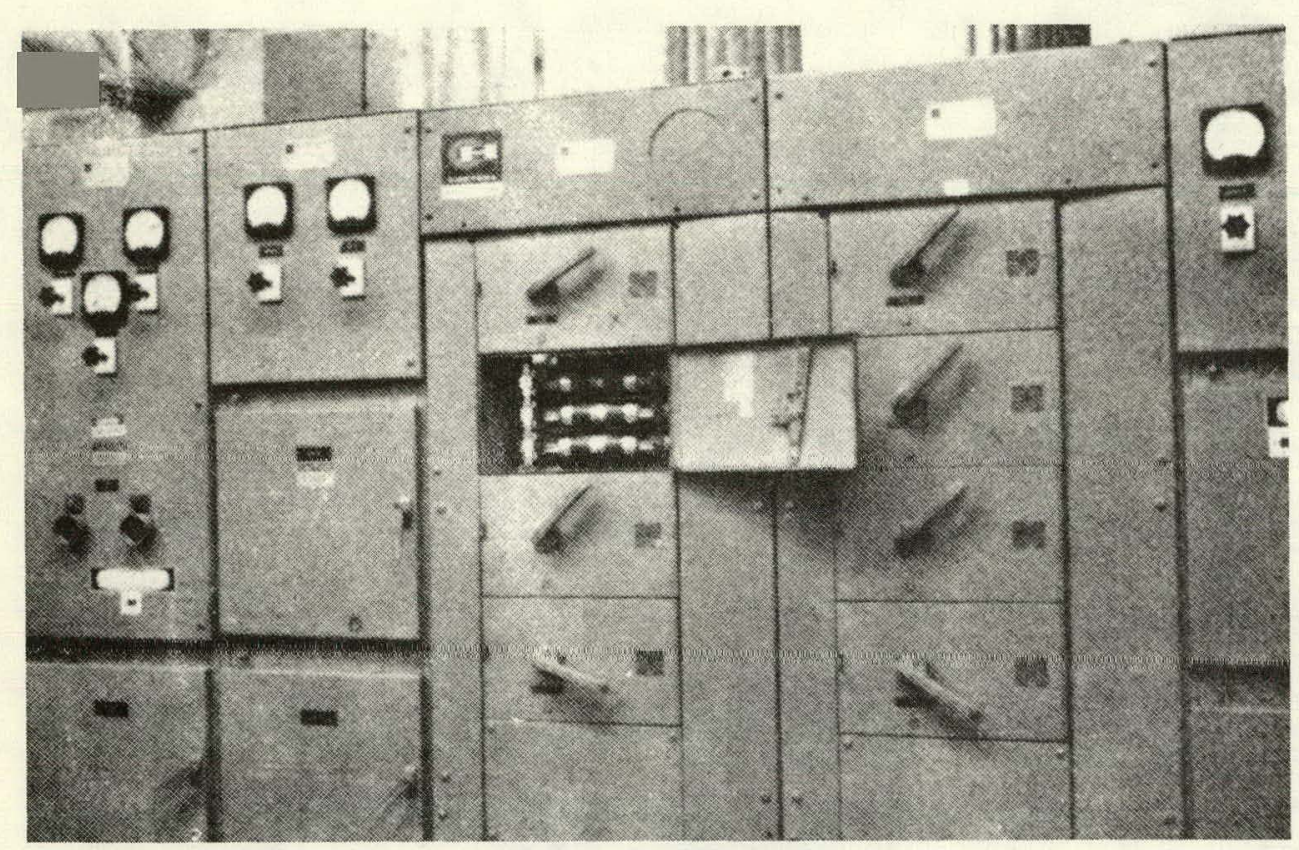

Photograph 3 shows a large motor control console for a heating and airconditioning system.

Thermogram 3

depicts an unbalanced three-phase circuit within one of the console's panels. 


\section{DETECTING NEED}

\section{FOR WEATHERSTRIPPING}

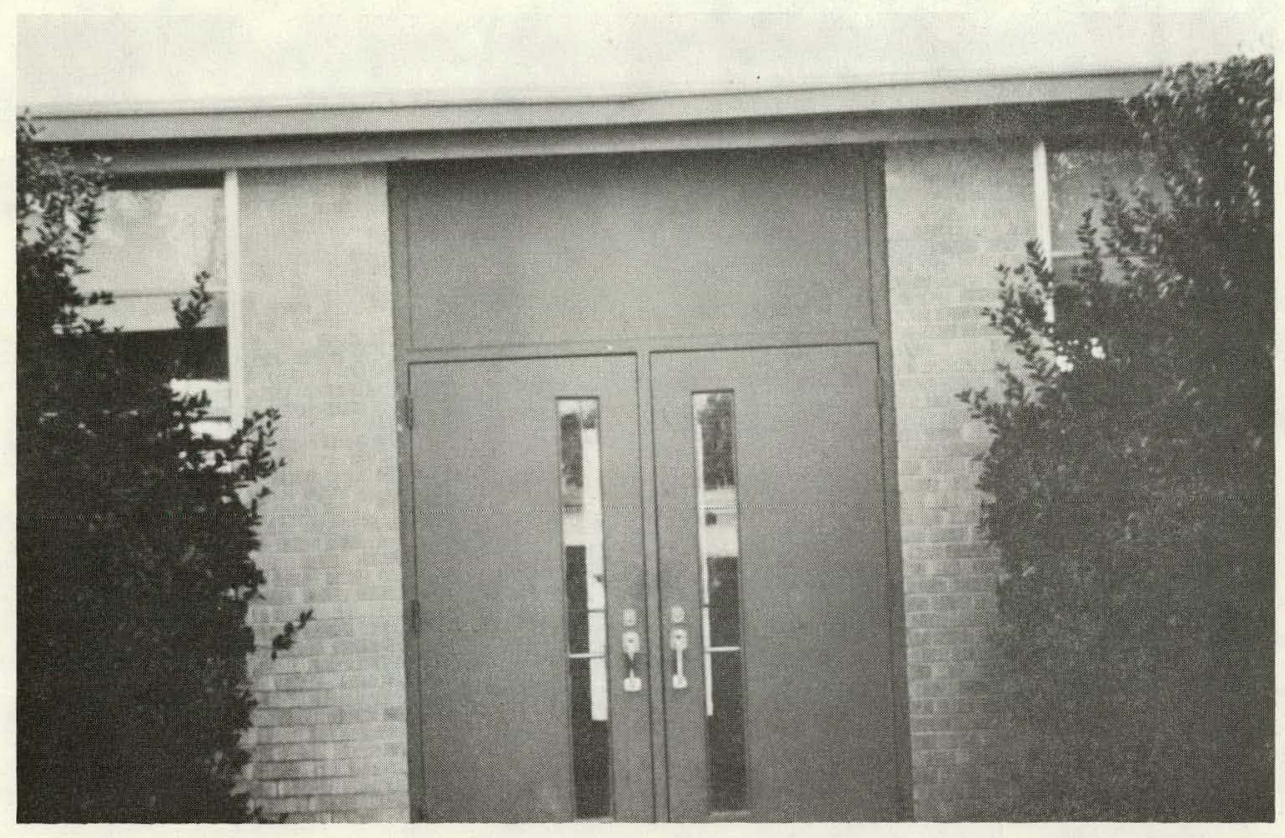

Photograph 4

shows a typical entrance to a school building.
Thermogram 4

shows heat loss from the single pane windows in the door and fivill between the door and casing, which indicates the need for weatherstripping.

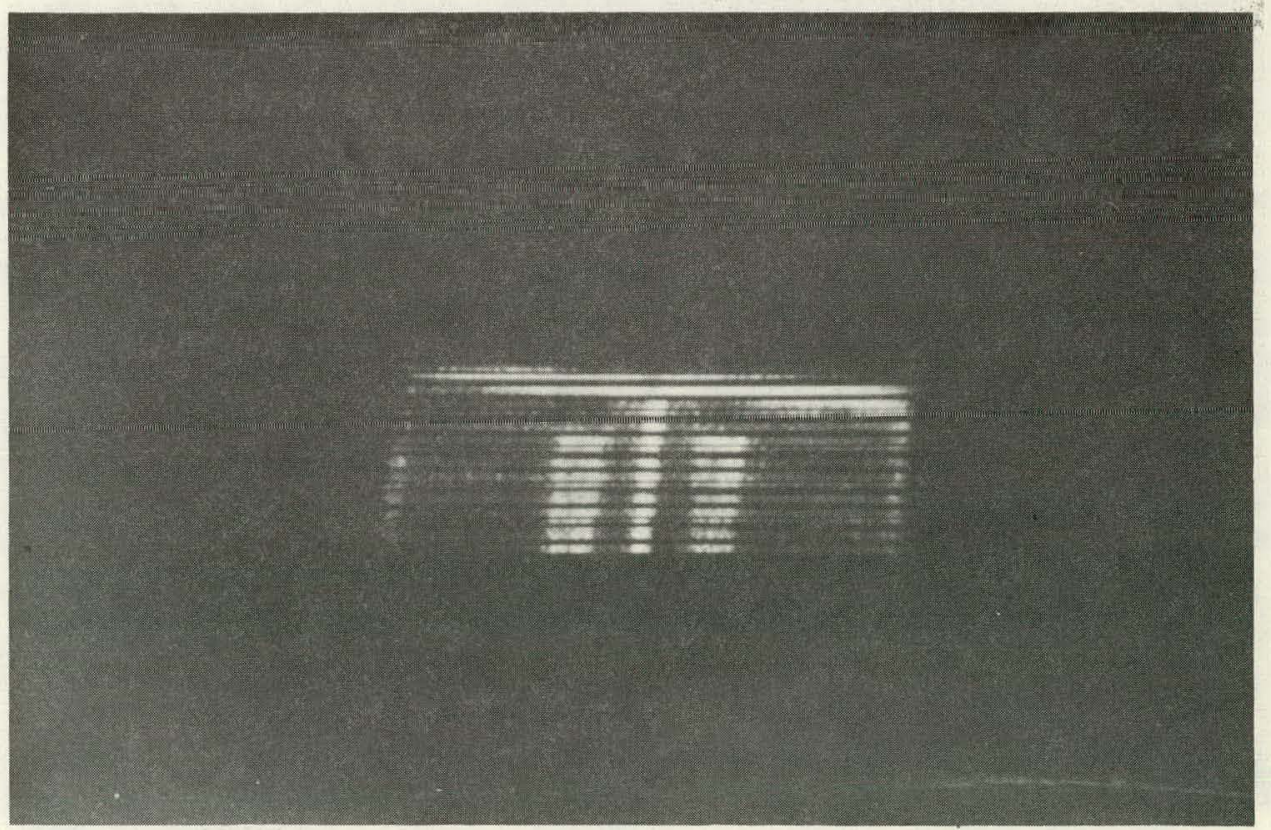




\section{DETECTING HEAT LOSS BETWEEN BUILDING PANELS}

\section{Photograph 5}

shows a typical bay of windows and overhanging roof of a school building.
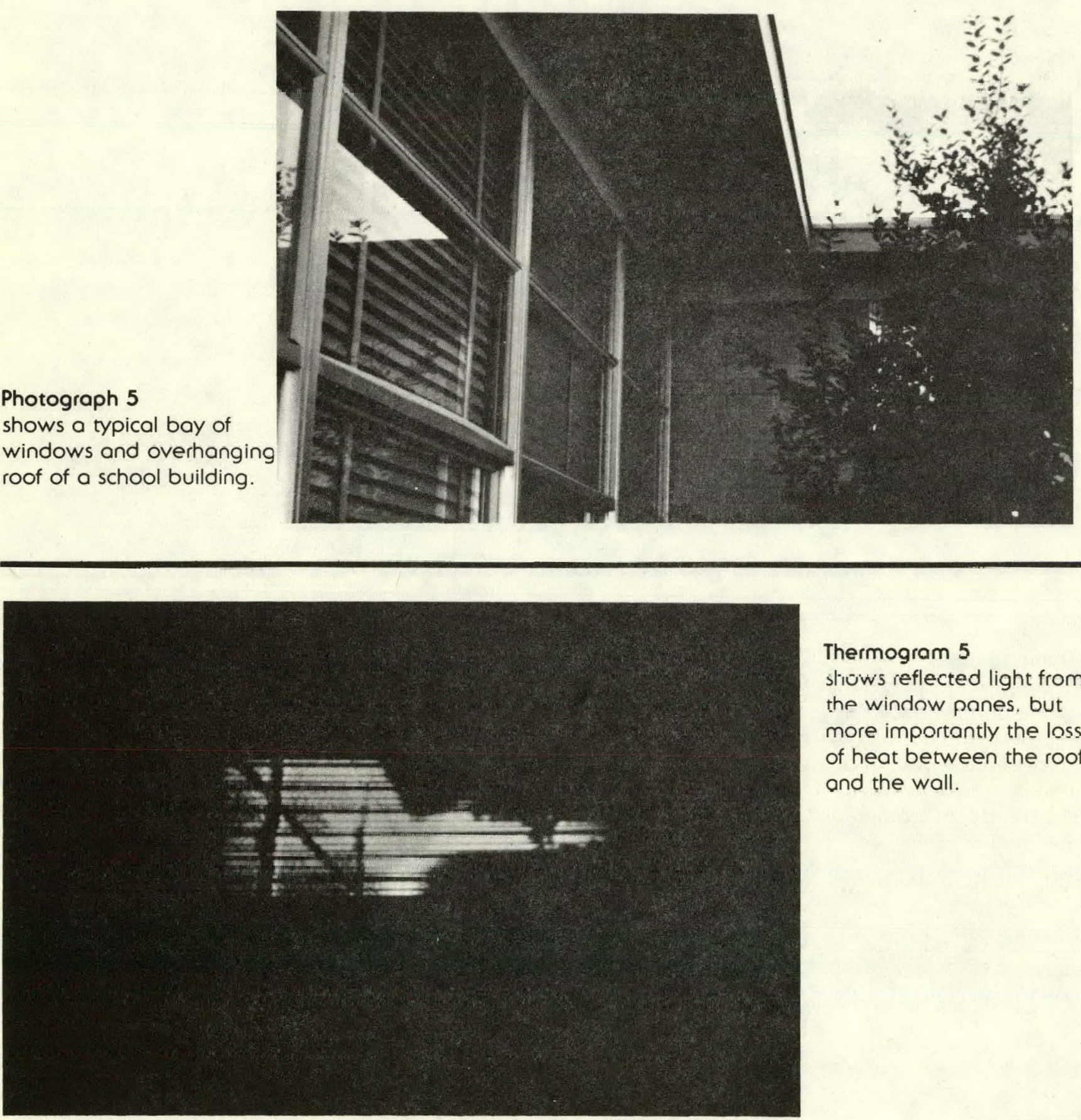

Thermogram 5

sliows reflected light from the window pones, but more importantly the loss of heat between the roof and the wall. 


\section{DETECTING HEAT LOSS DUE TO}

\section{WET ROOF INSULATION}

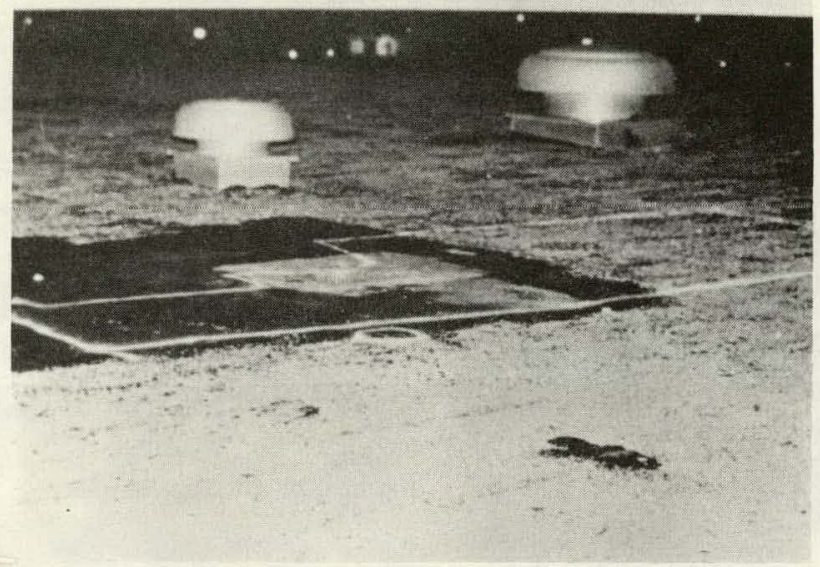

Photograph 6

provided by Infra-Scan of Vermont,

shows a flat roof with a built-in drain.

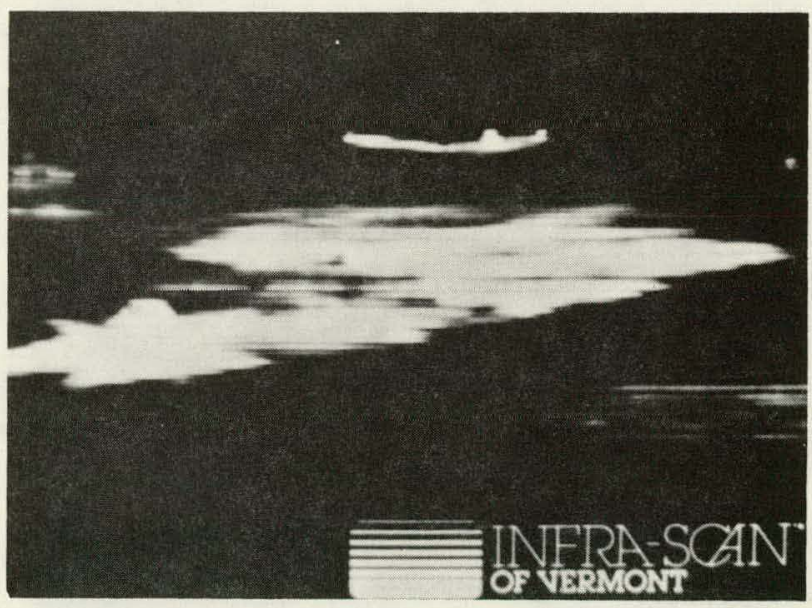

Thermogram 6

gives a good example of roof insulation damage. The irregular white areas indicate water damage. The white shapes in the upper right of the photo shows the location of the roof vent. The regularity of this light area indicates expected heat loss. 


\section{DETECTING POSSIBLE PROBLEM AREAS}

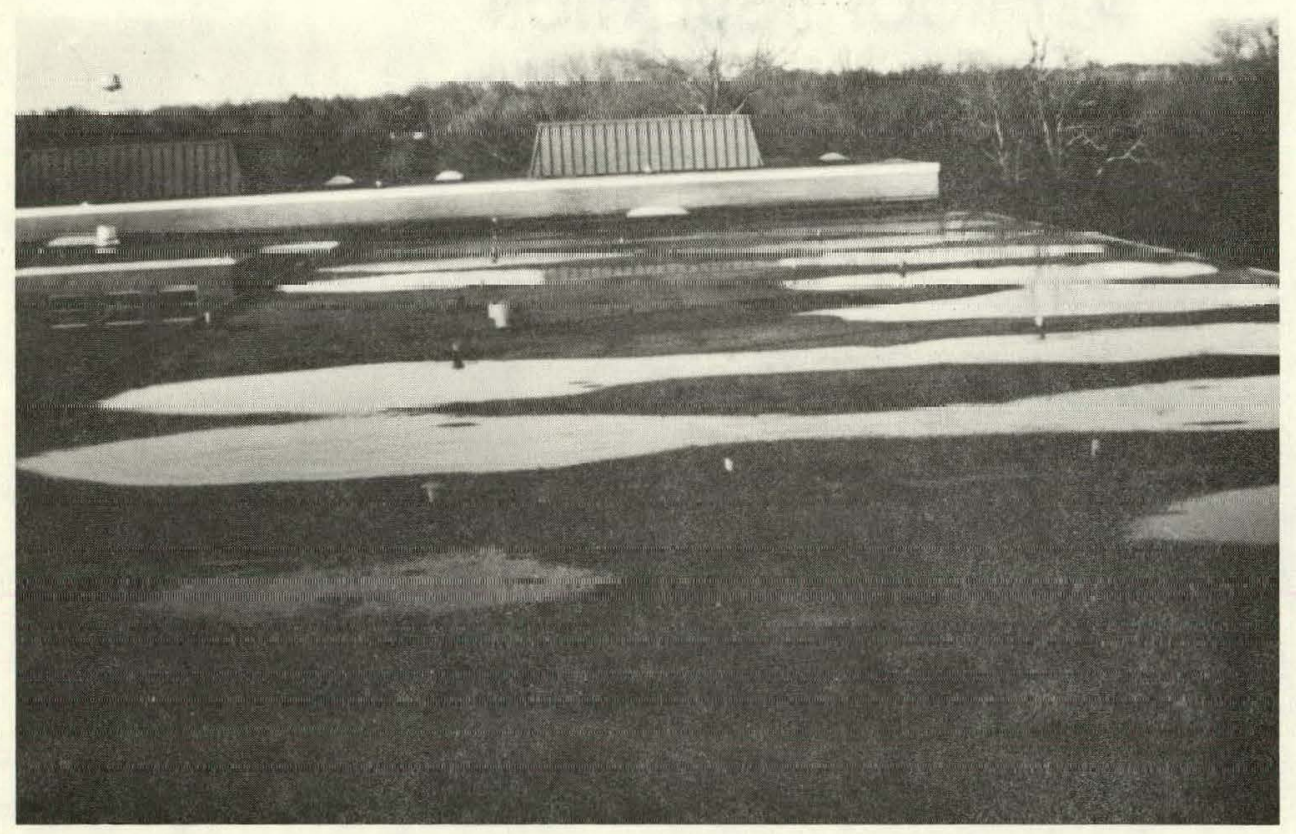

Photograph 7

shows standing water and ice on the flat roof of a school buildina. A roof in this condition should be checked for pusslble insulation damage.

Photograph 8

shows a technologist using an infrared scanner searching for heat loss due to wet or missing insulation.

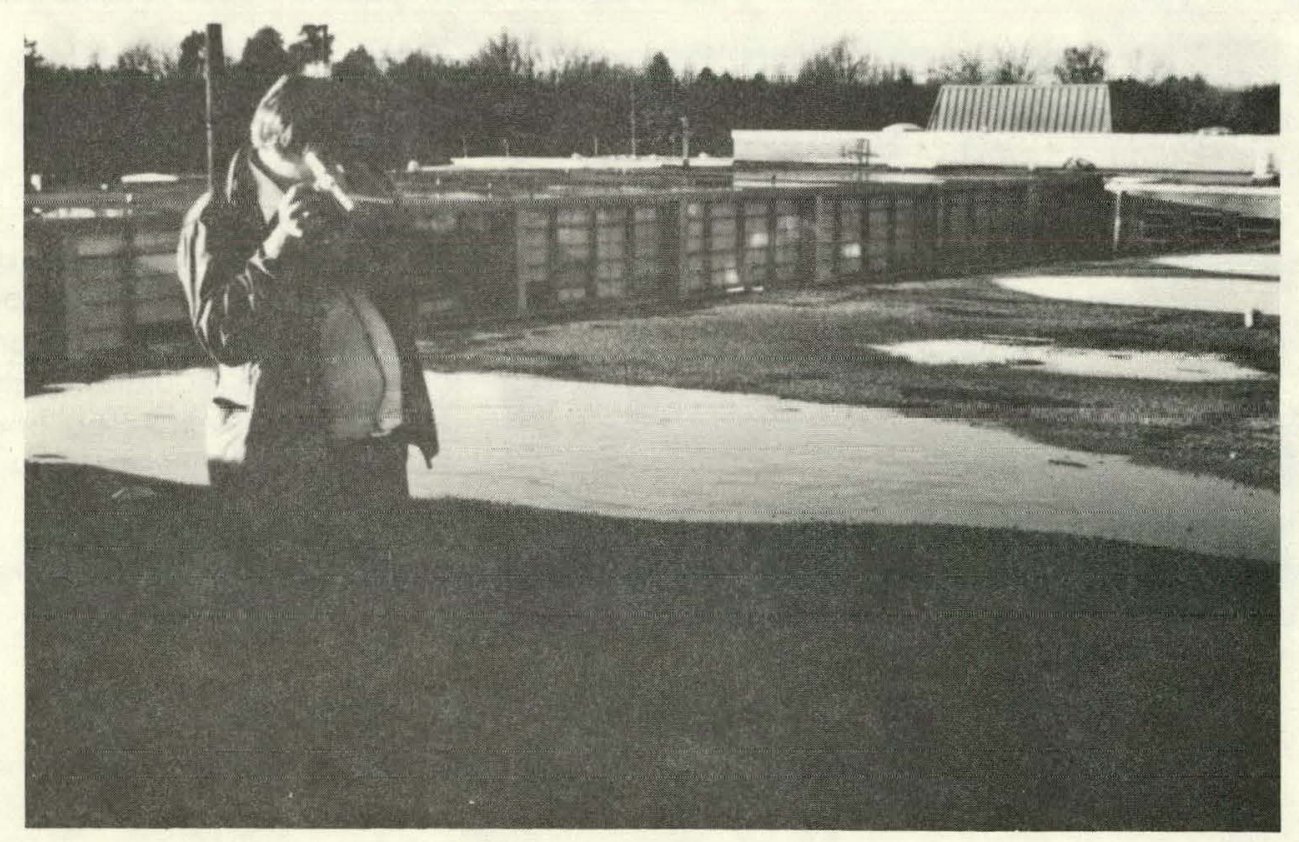




\section{IDENTIFYING SPECIFIC LOCATION WITH SCANNER}

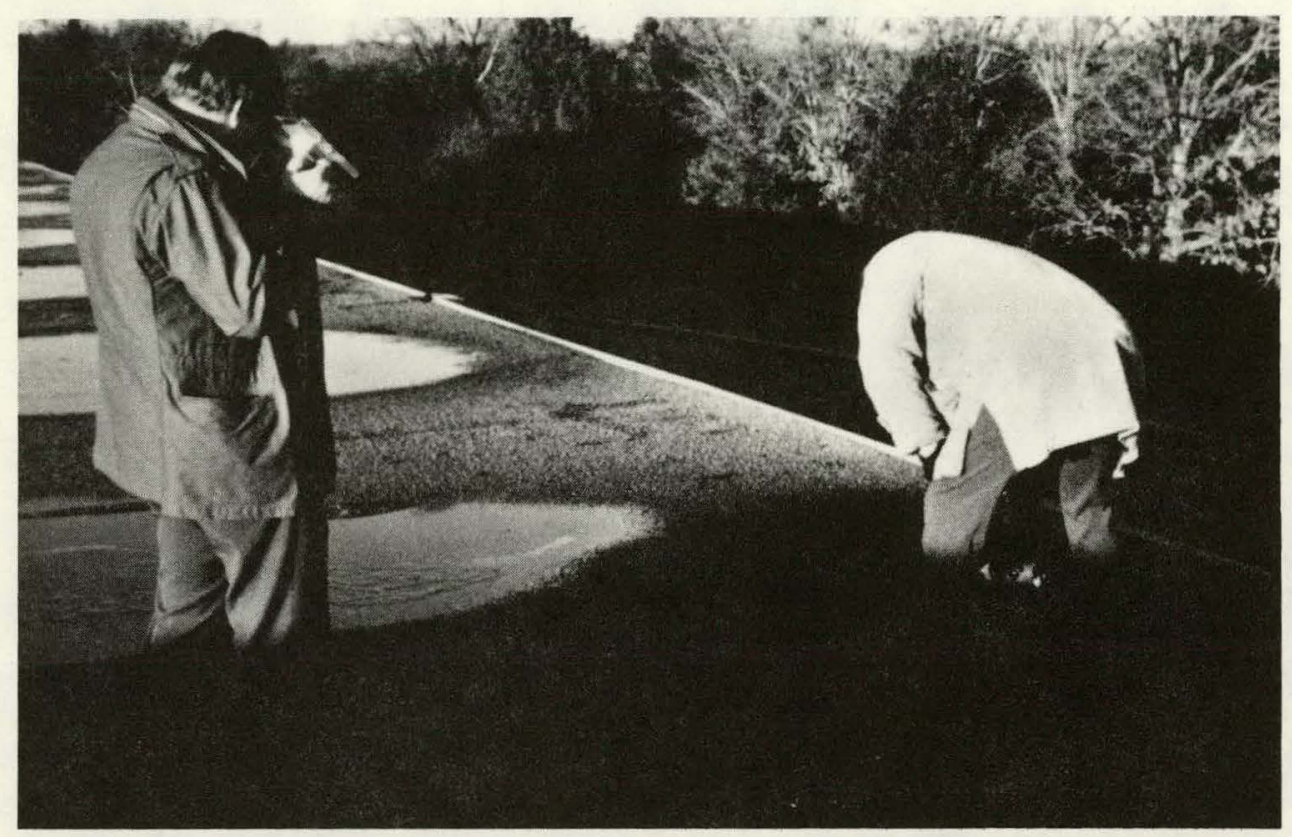

Photograph 9 shows an assistant marking areas with spray paint where the scanner has denoted heat loss through the roof.

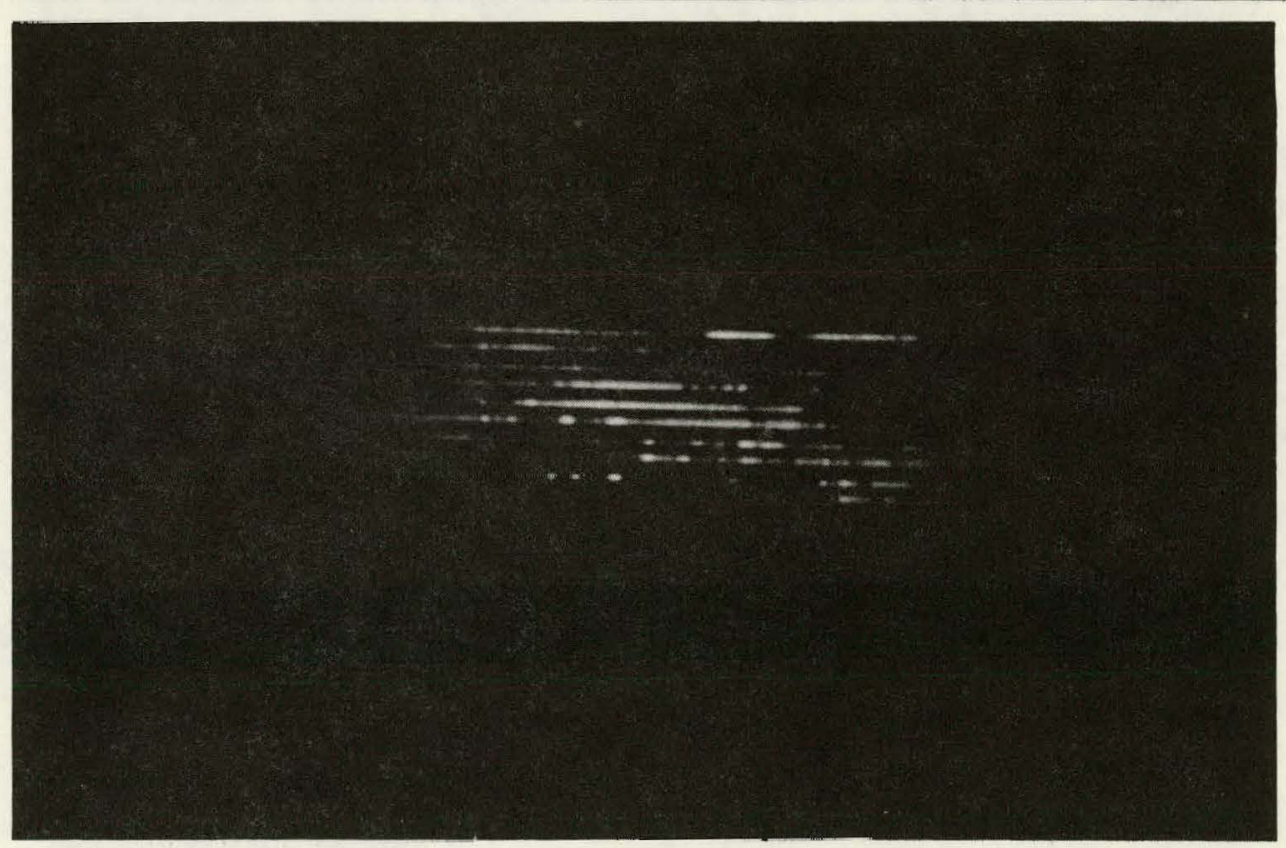

Thermogram 9

shows where the insulation is wet. The irregular pattern indicates that the moisture has spread throughout the insulation between the ceiling joists. 


\section{DETECTING LACK OF INSULATION IN WALLS}

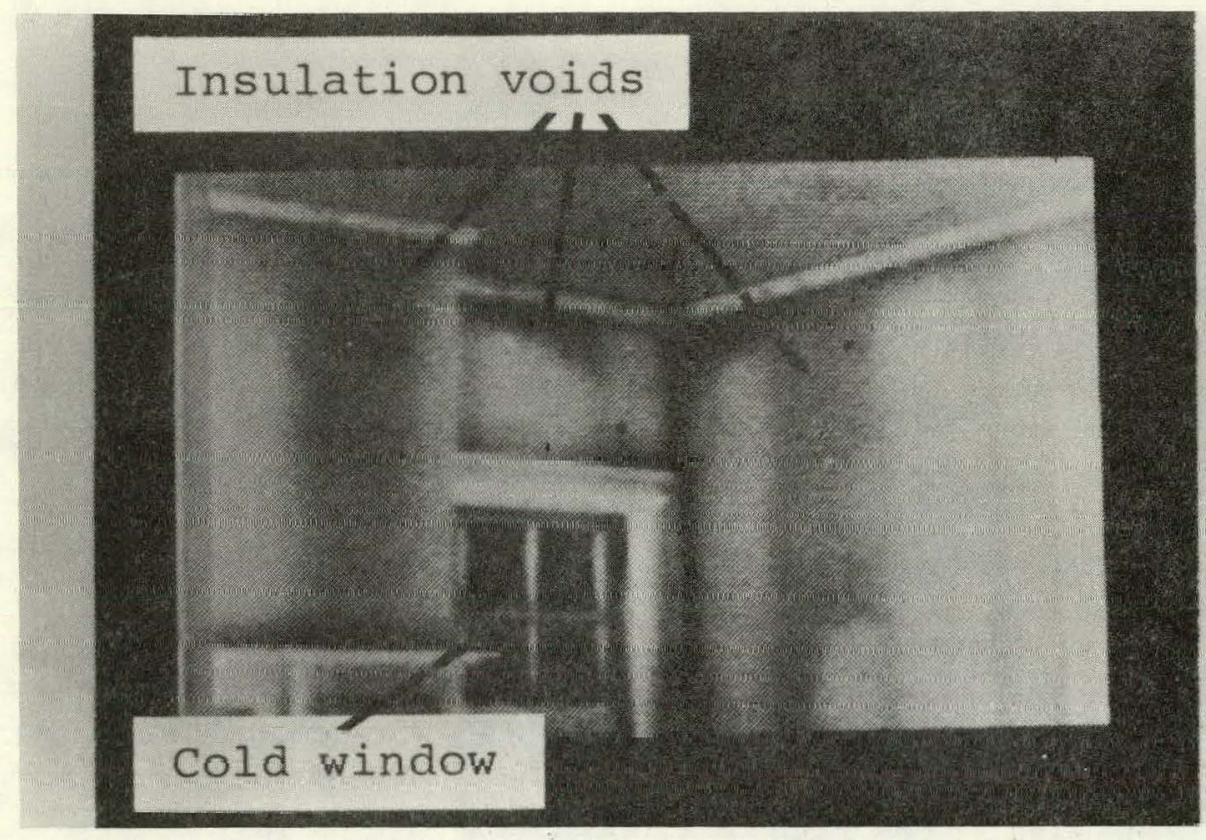

Thermogram 10

provides a good example of insulation voids in the interior and exterior walls of a building. * Note the gradations in shading indicating varying surface temperatures.

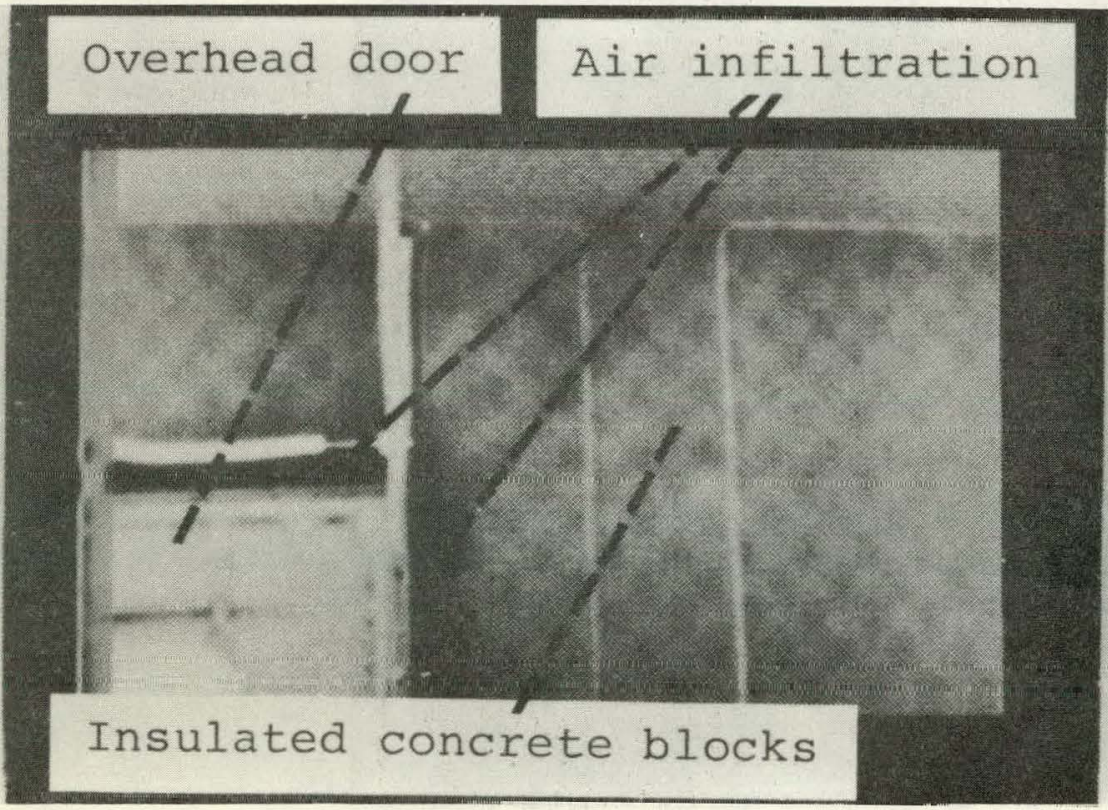

\section{Thermogram 11}

details air infiltration around a door.

* These thermograms show a black and white reversal as they are token from the inside of a room where the ambient temperature is warmer. 


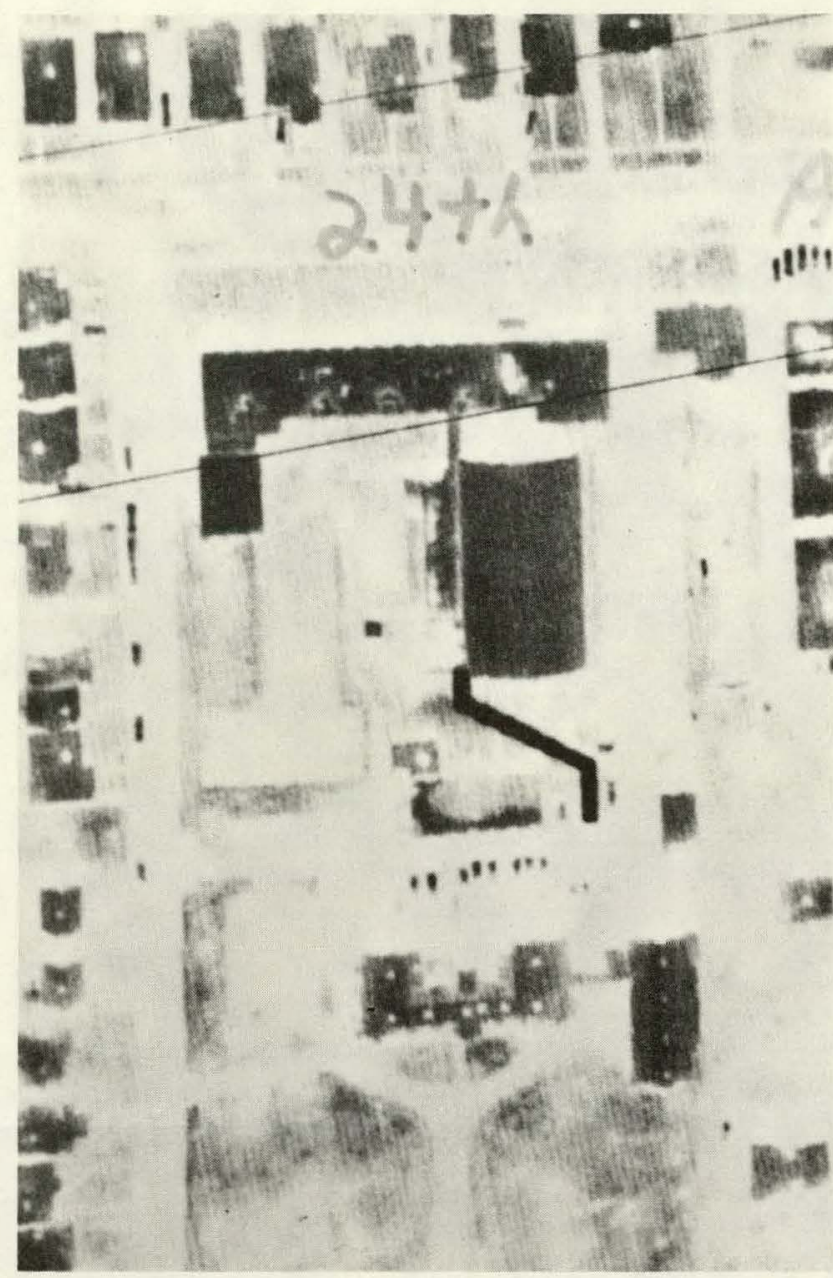

\section{DETECTING} ROOF HEAT LOSS BY AERIAL PHOTOGRAPHY

Thermogram 12

shows an aerial view of a school campus. The black angular shape in the center is a covered walkway. The regular white spots on the buildings are vents. Heat loss from these vents is expected. The white patches on the roof tops to the far right of the thermogram show wet or missing insulation.

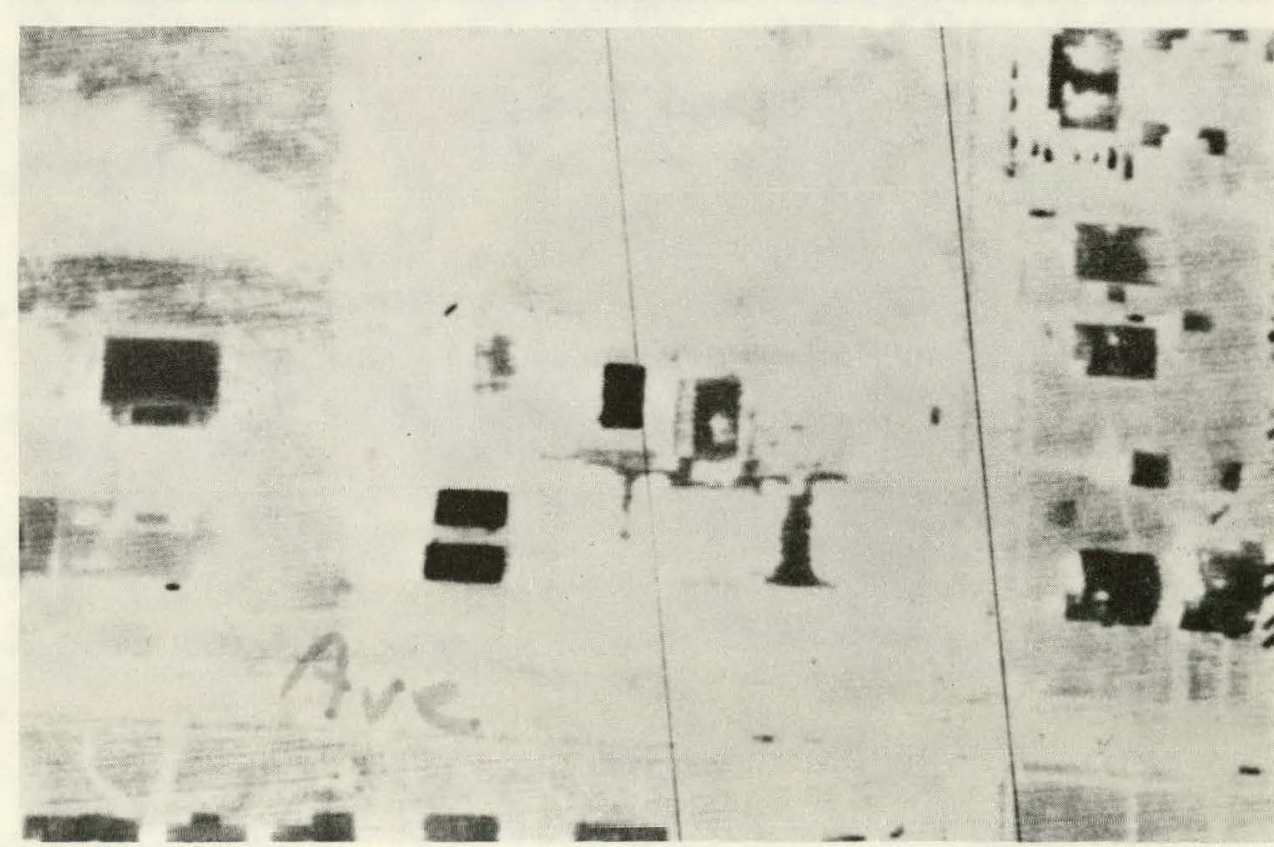

Thermogram 13

is another aerial view of the same campus. The solid black roofs in the left center indicate unheated buildings. The irregular white patches on the roof in the upper right hand corner of the picture indicate heat loss due to wet or missing insulation. 


\section{COMPARING DAMAGED}

\section{WITH UNDAMAGED ROOFS}

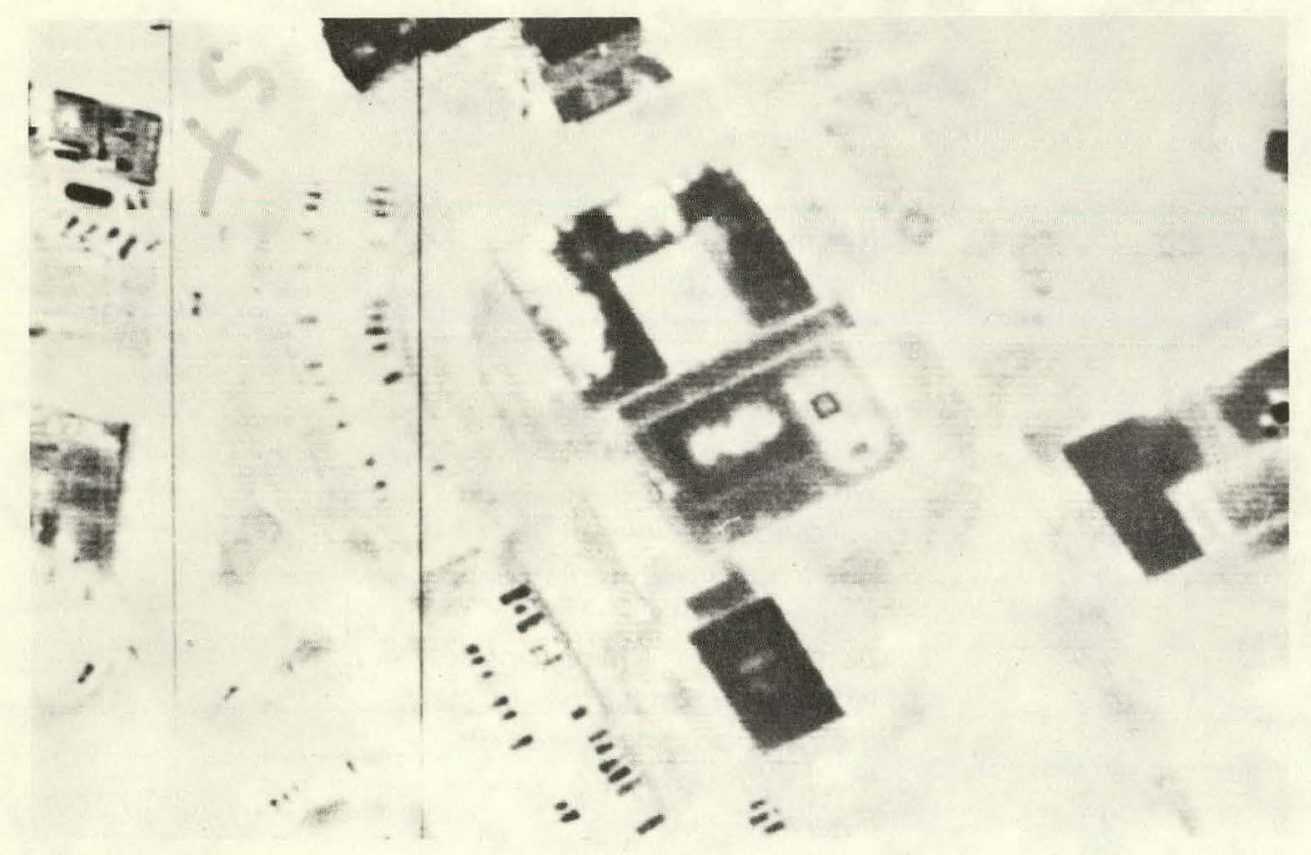

Thermogram 14

shows a large quadrangle on the campus. The roof in the very center shows extensive roof damage.

Thermogram 15

shows a larger quadrangle with adjoining buildings. The irregular white patches indicate roof damage. In the case of the roof to the lower left of center, the regular white rectangle is the result of heat escaping from around a vent or skylight and does not indicate roof damage.

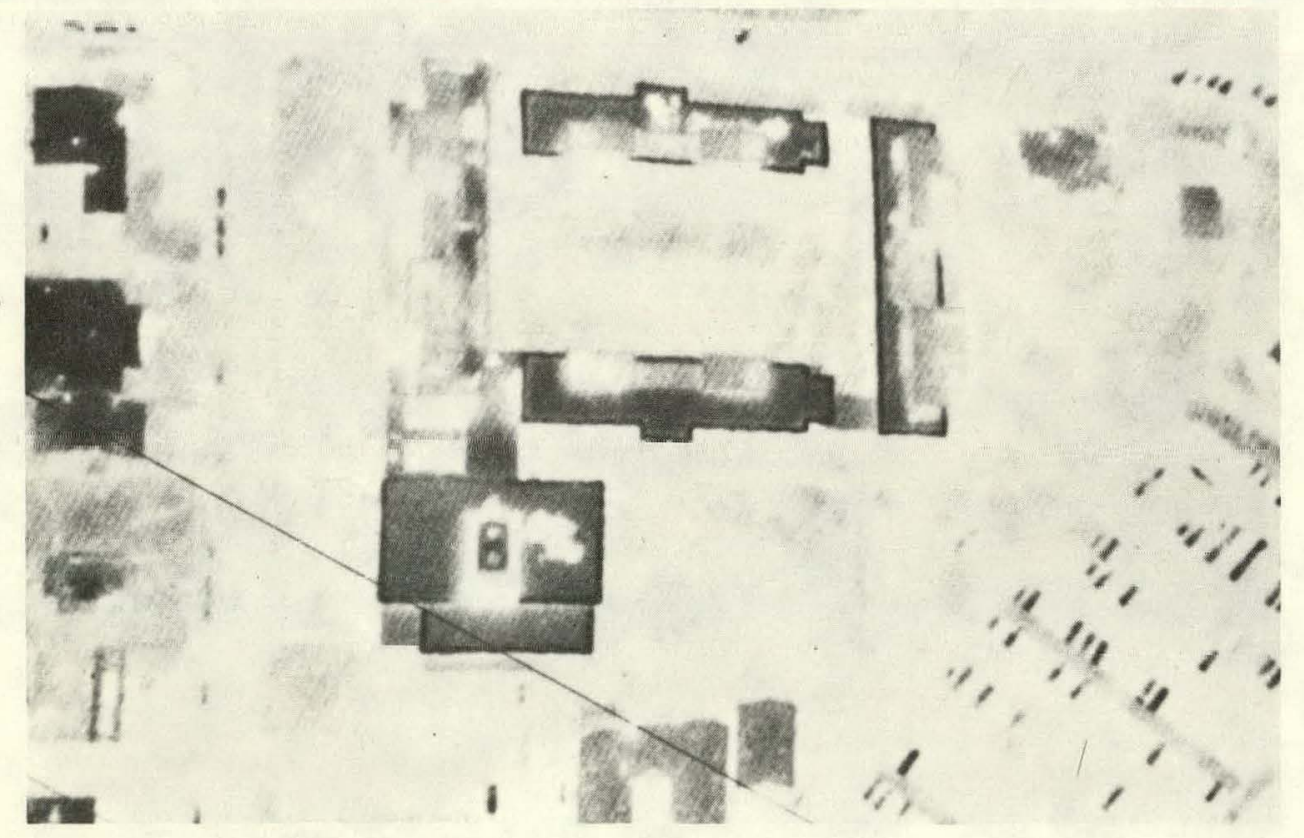




\section{ANNOTATED}

\section{BIBLIOGRAPHY}

Brown, R. J. and J. Cihlar (1978). Introduction to Aerial Thermography Applications in Energy

Conservation Programs. Canada Centre for Remote Sensing, Energy, Mines and Resources, Ottawa. Canada, Research Report 78-2, 25, p. 7. thermograms.

Aerial thermography is becoming widely used in many energy conservation programs as an aid in detecting heat losses. In order to realize the full potential of the technique, it is necessary that its advantages and limitations be appreciated. This report attempts to do this in a manner which is understandable to a person who does not have a technical background. A brief introduction to infrared theory is followed by a discussion of the detecting instrumentation and typical residential and industrial construction practices. Finally, examples of imagery are presented which attempt to illustrate the thermal appearance of features commonly encountered in thermograms of residential and industrial structures.

(reviewed in Marshall, Stephen J. Infrared Thermography of Buildings a Bibliography with Abstracts, 1979)

Christensen, David, B. Brainard \& J. Goddard Preliminary Evaluation of a Thermographic Scanning Device for Energy Conservation Studies. Huntsville: University of Alabama, Johnson Environmental \& Energy Center, 1978.

A thermal imaging system, the Magnavox AN/PAS-7 Point Detector/Scanning Mirror hand-held viewer, was used for a series of tests to measure hot spots (or heat losses) in a solar energy heating system, on the exterior of a nursing home, on a courthouse and a residence, and on power line transformers and substations. It was concluded that the AN/PAS-7 provides valuable information to aid in the evaluation of thermal systems because of its portability, ruggedness, wide field of view and adaptability. It can also be an important tool for use in the evaluation of solar energy conservation systems and could be especially useful for the evaluation of solar heating and cooling demonstration sites.

(reviewed in Marshall, Stephen J. Infrared Thermography of Buildings a Bibliography with Abstracts, 1979)

Dutt, G. S. and J. Beyea. Hidden Heat Losses in Attics-Thelr Detection and Reduction. Princeton, New Jersey, Center for Environmental Studies, Princeton University, May, 1979. (Report PU/CES 77 )

Dutt and Beyea surveyed 15 single family houses of various designs, using maximum-minimum thermometers. Their purpose was to determine whether the discrepancy they found between actual attic heat loss measured in town houses and that predicted by handbook calculations was present in other housing styles as well. In all cases, actual heat loss exceeded the predicted value. After further study, the authors conclude that some areas of heat loss can be easily eliminated in existing houses through retrofit, and all can be eliminated in new houses during construction.

This study is of interest in terms of energy conservation and heat loss, however it is of little value to those interested in thermography. 
Eden, Anthony \& John T. Tinsley. Second Interim Technical Report on USAFA Solar Test House. Colorado: U.S. Air Force Academy: Department of Civil Engineering, Engineering Mechanics \& Materials, September, 1977. Technical Report TR-77-34.

The following abstract written by the authors details the contents of the publication:

\begin{abstract}
"This report describes the continuing performance of the first retrofit-constructed, solar-heated facility in the USAF, the Solar Test House at the USAFA. The attempts at improving the performance of the system have centered on the following: additional heat exchangers; bleed air line and valves; ground array angle changes; reduce volume of storage tank control temperature reductions; flow rate reductions and new data gathering system. The Solar Test House was modified to conserve thermal energy by using urea foam insulation in the ceilings, vestibules on the doors, and linear diffucors for the duct outlets. Thermography studies have been started tu explure lhe flow patterns through the solar arrays and correlate pictures with multiplexed sensor readings. Dally, monthly and yearly data analysis is reported to shiow llie elfecls of the various system and operational changes and the improved performance."
\end{abstract}

Goldstein, R. J. Ramsey and Hain. Determination of Building Heat Loss and Thermal Integrity Using an Airborne Infrared Scanner-Comparison of Ground Based and Thermographic Measurements. Minneapolis, Minnesota, Department of Mechanical Engineering, Institute of Technology, University of Minnesota, 1978.

"Thermographs obtained with an airborne infrared scanner are compared to ground level observations for a number of buildings. Single family residences were studied as well as buildings at a university and at a middle school/high school complex.

The density of the images on the thermograph are determined using a precision densitometer. The ground-based observations include roof-surface temperature determinations with thermocouples and resistance thermometers, direct measurement of heat flux through roof structures, and an estimate of thermal resistance from a knowledge of the structural components and the insulation present. Comparison of the optical and ground-based measurements provides intormation on the potential of infrared thermographs for determining the building heat loss and the thermal resistance of structures."

(The above entry is the abstract prepared by the authors.)

Harrje. D. T., G. S. Dutt and J. Beyea. Locating and Eliminating Obscure but Major Energy Losses in Residential Housing. Princeton, N.J. Princeton University. (To appear in ASHRAE Transactions, 85, Part II (1979))

The abstract prepared by the authors follows:

"Mujui el ielyy lusses In resldentlal bulldings can prove very elusive to the energy auditor. This paper outlines a number of experimental approaches for determining the energy consumption of a building, with emphasis on air infiltration. The combined use of depressurization of the house and infrared scan permits the location of "bypass" routes through which warm air is leaving the structure. These losses tend to undermine the effectiveness of insulation, as well as to lower comfort in the dwelling. Several types of bypasses are described and evidence for their widespread existence is documented. The impact of retrofitting these and other energy loss sites is also discussed with regard to side effects on the occupants and building structure." 
Link. L. E.. Jr. (1976). Procedures for the Systematic Evaluation of Remote Sensor Performance and Quantitative Mission PIanning. Mobility and Environmental Systems Laboratory. U.S. Army Engineer Waterways Experiment Station, P.O. Box 631, Vicksburg, Mississippi, 39180. Technical Report M-76-8.

The purpose of this study was (1) to quantitatively examine the natural phenomena that influence the information content of remote sensing imagery obtained in the visible and infrared (IR) portions of the electromagnetic spectrum, and (2) from the knowledge gained through these examinations, to develop analytical tools for planning remote sensing missions and provide guidance for application of photographic and thermal IR sensor systems to civil engineering and environmental problems.

This study consisted of the development of analytical models that allows systematic control of the major variables that influence the character of imagery produced by photographic and thermal $\mathbb{R}$ remote sensing missions. The basic concept of the models and the mission planning tools is an organized and quantitative means for evaluating photographic and thermal IR sensor systems for particular data acquisition jobs by contrasting the magnitude and spectral content of energy received by the sensors with performance characteristics of the sensor systems. The ability to quantitatively predict performance provides the capability necessary to quantitatively plan missions for specified types of data. Variables considered include the source of electromagnetic radiation, interactions with terrain materials, interactions with the atmosphere, sensor altitude, time of day, time of year, source-sensor position, and sensor spectral and spatial characteristics.

(reviewed in Marshall, Stephen J. Infrared Thermography of Buildings, a Bibllography with Abstracts, 1979)

Lukens, John E. \& T. L. Flynn. Thermography and Energy Conservation.

This pamphlet gives a brief overview of the fundamentals of thermography, its effective use, and the costs and benefits associated with thermographic scanning for energy conservation. As an initial introduction to thermography, or to present to a school board supplemental to more thorough information, this pamphlet can be useful. The annotated thermogram on the cover graphically describes the result which can be expected when a thermogram of a building is made.

Madding, Robert $P$. (ed.) Thermal Infrared Sensing Applied to Energy Conservation in Building

Envelopes. (Thermosense III). The Society of Photo-Optical Instrumentation Engineers,

Bellingham, Washington, 1981.

This collection of conference proceedings is geared to current and potential users of thermal infrared sensing for conserving energy. Emphasis is on applications to commercial, institutional and residential building envelopes. Articles include an introductory talk on thermography and its application to investigating heat loss in structures, a review of how heat flow in structures relate to surface temperatures, interpretation of thermograms, practical and theoretical aspects of using thermography to implement energy audit and conservation programs, establishing retrofit priorities, practical experiences in the use of thermography and trends in thermal sensing.

Marshall, Stephen J. Infrared Thermography of Buildings, A Bibllography with Abstracts. U.S. Army Cold Regions Research and Engineering Laboratory, Hanover, New Hampshire. Order from Research and Development Office, Chlef of Engineers, Washington, D.C. 
The following abstract is taken from the report:

"This report contains annotated abstracts of over 100 reports (66 more than the 1977 edition) on the new, but rapidly expanding subject on infrared thermography of buildings. Infrared thermography of buildings (IRTB) is a rapid, noncontact, real-time technique that uses an infrared thermal imaging system to detect heat loss or gain, structural defects, moisture, and other anomalies in building envelopes. Photographs (thermograms) or video recordings of the imagery provide hard-copy documentation of faults detected. The references cover remote sensing airborne surveys of large numbers of buildings, close-up ground surveys of individual buildings, and qualitative (speculative) and semi-quantitative (ground-truth) field surveys. The report presents examples of thermographic energy audits, roof moisture surveys, building retrofit surveys, solar panel analysis, window assessments, and other practical applications by government agencies and private sector survey teams. It lists research and development efforts to provide fundamental information to improve quantiflcation accuracy, evaluate equipment, and develop interpretation standards, along with examples of daily usage in contract specifications, public awareness programs, and product testing:"

Mill, Peter A. D. Development of PWC Capability in Thermographic Diagnosis of Building Envelope Deficiencies. Report Series \#27, Public Works, Canada, 1979.

Public Works Canada used thermography to quickly identify buildings with enclosure defects and to diagnose their causes. While the cost for retrofitting buildings was high, the study finds that much of this cost could have been avoided had thermography been used during early stages of building occupancy.

The results of this study indicate that ground and aerial thermographic techniques yield significant maintenance and retrofit cost savings. The importance of correct interpretation of thermograms is stressed.

This report also provides a brief overview of thermography and its relation to building in ives llgation, and thermographic equipment. The report is written in both English and French.

Mill, Peter A. D. Thermographic Diagnosis of Building Envelope Deficiencies. Report \#28. Minister of Supply \& Services, Canada, 1979. (Order from Public Works Canada/Technological Information/Sir Charles Tupper Building/Riverside Drive/Ottawa KIA OM2).

This report details two thermographic surveys carried out by Public Works Canada. The first survey identified energy-loss areas on the building. Steps were taken to remedy the problem on one wall, after which a second thermographic survey was done. This survey showed that the retrofit was successful. Retrofit of the other external walls was performed.

Mill, Pëler A. D. Thermography-A New Building Science İool, Report Series \#29, Minister of Supply and Services Canada, 1979. (Order from Public Works Canada/Technological Information/Sir Charles Tupper Building/Riverside Drive/Ottawa KIA OM2).

This paper was presented at the Fourth Biennial Infrared Information Exchange in St. Louis, Missouri, August 22-24, 1978. It describes some principles involved in building performance investigations, phenomena encountered and techniques employed. Thermography is judged to be useful in evaluating building deficiencies when used by individuals with building science knowlege. 
Miller, Robert A. (ed.) Proceedings of the Fourth Biennial Infrared Information Exchange, August 22-24, 1978. St. Louis, Missouri.

This conference proceedings has several articles which would be of interest to administrators who wish to know about the technical aspects of remote sensing. Among these articles are a paper on wet roof insulation detection, a paper on roof thermography and a paper evaluating hand-held infrared thermometers.

Munis, Richard H. Berger, Marshall \& Bush. Detecting Structural Heat Losses with Mobile Infrared Thermography, Part I.Description of Technique. Cold Regions Research and Engineering Laboratory, Hanover, New Hampshire, October, 1974.

This report describes the methods used in applying infrared thermography to detecting structural heat loss. Topics covered include the principle of the IR scanner, advantages of its use, and other potential applications. Of interest are annotated photographs of actual thermograms.

Munis, R. H., S. J. Marshall and M. A. Bush. Detecting Structural Heat Losses with Mobile Infrared Thermography, Part III-Survey of USA CRREL. December, 1975.

This report provides a description of excessive heat losses in the USA CRREL building. These heat losses were detected using a mobile infrared thermography system. The report also discusses the need to carefully monitor weather conditions before starting a building survey, as the effects of radiant energy from the sun may interfere with analysis by masking the heat emanating from within the building.

Munis, R. H. (1977) How to Reduce Heating Costs Without Alternative Energy Sources. DM

Publications, Thetford Center. Vermont, 2 thermograms, 58 pages.

This book is addressed to do-it-yourself homeowners who are interested in how to correctly and effectively insulate their houses. It outlines the first steps toward learning the facts about house insulation. It introduces the terminology used by building and insulating contractors, and explains why very few of them have been able to insulate houses successfully to cope with today's high cost of energy.

Most important, as a pioneer in the use of infrared thermography to pinpoint insulation deficiencies in buildings, the author explains and demonstrates the entire process of insulating correctly to effect a dramatic reduction in fuel bills. No one showed him; he acquired this information the hard way. He not only demonstrates the techniques of effective insulating but describes the essentials of various types of insulation.

The author dispels several popular myths about insulating. He shows how to insulate a house to both save money and have a more comfortable, draft-free house.

Most people believe that insulating a house can be done only by an experienced contractor. But the author describes techniques that most contractors are not even aware of. Although many people enjoy doing carpentry work, some may not be interested in becoming involved with insulating. These people are missing the satisfaction of creating a warm and comfortable house while at the same time enjoying the praise of family, friends, and neighbors for being able to lower heating costs. This book offers an alternative to having high heating costs and an uncomfortable home.

(reviewed in Marshall, Stephen J. Infrared Thermography of Buildings a Bibllography with Abstracts, 1979) 
Munis, Richard, Marshall, Bush. Detecting Structural Heat Losses with Mobile Infrared Thermography, Part IV.Estimating Quantitative Heat Loss af Dartmough College, Hanover, New Hampshire. Cold Regions Research and Engineering Laboratory.

The following abstract is taken from the document:

During the winter of 1973-74 a mobile infrared thermography system was used to survey campus buildings at Dartmouth College, Hanover, New Hampshire. This report provides both qualitative and quantitative data regarding heat flow through a small area of a wall of one brick dormitory building before and after installation of aluminum reflectors between radiators and the wall. These data were used to estimate annual cost savings for 22 buildings of similar construction having aluminum reflectors installed bohind 1100 radiators. The data were then eomieared with tlie ucluul suviriys which were calculated from condensate meter data. The discrepancy bofwcon cotımated and actual annual cost savirigs is explairied in delull along with all assumptions required for these calculations.

Munis, R. H. and S. J. Marshall (1977) Infrared Thermography of Buildings: Qualitafive Analysis of Window Infiltration Loss, Federal Office Building, Burlington, Vermont. CRREL Research Report RR77-29, 28 thermograms, 17 pages.

"An interior, infrared thermographic survey of single-pane, aluminum-frame, projected windows was performed to pinpoint locations of excessive infiltration. Infrared thermographic inspection accomplishes this more quickly and more accurately than conventional techniques of studying window infiltration. This report presents 32 thermograms and photographs, which in many cases dramatically illustrate infiltrations 1) around the mullions, 2) along the top opening cracks, and 3) under the frame/sill interfaces. Poor glazing seals were easily detected and the exact points of glass/frame leakages were pinpointed. Plumes of warm air on the window glass, rising from the convectors, were dramatically captured by the infrared camera system. In several cases, the plumes were noted $12 \mathrm{ft}$. above the convectors on the top window panels. Heat loss from the convectors was noted through the walls of the building in thermograms taken from the outside. Several recommendations were prepared for the General Services Administration, owner of the Federal Office Bullding in Burlington, Vermont."

(reviewed in Marshall, Stephen J. Infrared Thermography of Buildings, a Bibliography with Abstracts, 1979.)

Munis, R. H. (1975) Thermography: A New Way to Profit from the Energy Crisis. Hicksville, New York: Exposition Press, Inc., 2 thermograms, 45 pages.

This book outlines an annotative, existing technology that promises to become, within the next five years, the single most important technology for effecting energy conservation in all buildings across the United States-infrared thermography.

Infrared thermography uses an infrared camera system to detect heat radiated from an object. and can be employed to pinpoint the locations of wasteful and costly heat loss and gain in every conceivable type and size of building. The book emphasizes that a short-term solution to the Energy Crisis can be obtained only by adequately insulating every building in this country-and infrared thermographic inspection is the only method by which the effectiveness of a building's insulation can be monitored. 
The author gives a detailed explanation of this technology and its potential as a new and lucrative business (i.e., how a building heat loss inspection service can be established and profitably operated), and illustrates that no new technologies are required to assist homeowners, businessmen. and industrialists.

Photographs of the AGA Thermovision Infrared Camera System are included as well as thermograms ("heat pictures") showing costly heat loss.

(reviewed in Marshall, Stephen J. Infrared Thermography of Buildings a Bibliography with Abstracts, 1979)

New England Innovation Group

Energy Conservation Measures for the Woodstock Union High School, Woodstock, Vermont.

This report details cost-effective energy conservation opportunities for a high school, using a thermographic energy audit. Of particular interest to school superintendents who are considering using this technique are a discussion of the cost-effectiveness of each retrofit, and the actual photographs of thermograms which are included. These pictures illustrate what type of data is. produced using infrared remote scanners on the ground level.

\section{Cost Payback Analyses for Energy Conservation Measures, Woodstock Union High School, Woodstock, Vermont.}

This report summarizes the cost payback features of all recommendations made by the New England Innovation Group concerning the retrofit of Woodstock Union High School. Its value to school administrators is illustrative of the type analysis which can be expected if a thorough building survey is completed.

Pettersson, Bertil and B. Axen, Thermography, Testing of the Thermal Insulation and Airtightness of Bulldings. Stockholm: Swedish Council for Building Research.

This rather technical publication explores the feasibility and reliability of the IR camera in detecting insulation defects and heat leaks in buildings, and develops procedures for applying thermography to this purpose. Topics covered in the book include the methodology of thermography, energy consumption, rules for interpreting thermograms and examples of actual defects as exposed by thermography.

While the book focuses on information for the technician, it provides a good overview of thermography and its application to heat loss studies in buildings.

Texas Instruments Inc. (1978) Aerial Infrared Thermograms and Residential Heat Loss. Texas Instruments Ecological Services, Dallas, Texas 75222, 13 thermograms, 34 pages.

The production of infrared thermograms as indicators of heat loss in residential and business structures involves the application of thermal infrared technology to the problem of conservation of energy. One approach involves overflying cities and towns at night in an airplane equipped with an infrared scanner which works much like a light meter in the long-wave infrared portion of the electromagnetic spectrum. The scanner, like a television set, generates a picture line by line rather than all at once like a framing camera. One dimension of the image is produced by scanning side to slde and the other dimension is produced by the forward motion of the aircraft. 
The micro- and macro-environments surrounding a community are a heterogeneous mixture of substances that are continuously reflecting, refracting, absorbing, and emitting infrared energy. The vast majority of the energy in this envelope originates from the sun, whose surface approximates a blackbody radiator at $6000 \mathrm{~K}$.

Interpretation of an infrared thermogram for heat-loss informatin involves a great deal more than merely looking at the picture and making general statements about the observation. For example, an object or roof that shows extremely light in tone is often referred to as HOT, and one that shows extremely dark is called COLD, when their temperatures actually may vary by only a few degrees and both could be what would usually be termed COLD (e.g., in the neighborhood of $25^{\circ} \mathrm{F}$ ). The contrast between the light tones and dark tones is not only a function of the actual temperature and emissivity differences that exist for the objects, but a function of image recording and image printing settings and techniques.

Aerial infrared scanning of residential and business structures is a cost-effective way to provide heat-loss information useful to energy conservation efforts and is a first step in helping homeowners meet rising utility bills. But the effectiveness of these programs can be lost if the information gained does not reach the publlc.

(reviewed in Marshall, Stephen J. Infrared Thermography of Buildings a Bibliography with Abstracts, 1979)

Thermosense I. First National Conference on the Capabilities and Limitations of Thermal Infrared Sensing Technology in Energy Conservation Programs, Chattanooga, Tennessee, $20-21$ September 1978. The American Society of Photogrammetry, 105 Virginia Avenue, Falls Church, Virginia 22046.

These conference proceedings contain the papers from three sessions. The first session covers the basic aspects of infrared radiation, heat loss through structures and the use of airborne and ground based sensors for monitoring infrared radiations. The second session includes a series of case studies where this equipment has been used in energy conservation programs. The third session provides information concerning the progress, pitfalls and potentials of applying infrared sensing ter.hnolngy.

These proceedings are useful as they speak to both technologists and consumers of infrared sensing devices.

Thermosense. II. Second National Conference on Thermal Infrared Sensing Technology for Energy

Conservation Programs. Amerirnn Snciety of Photogrammotry.

Thermosense II, contains the proceedings from the second conference concerning the use of infrared technology for heat loss surveys. Topics included in the conference were ground-based as well as aerial scanning techniques, basic principles, case studies, performance standards, and future pntentials.

Thermosense III. Thermal Infrared Sensing Applied to Energy Conservation in Building

Envelopes. Robert P. Madding, editor. Proceedings: The Society of Photo-Optical Instrumentaion Engineers. 254, 1981.

The third conference on thermography was devoted to sessions helpful to current and potential users of thermal infrared sensing for conserving energy. Emphasis was on applications to building envelope analysis. Sessions included information on programs for using thermography to implement 
energy audit, conservation, and retrofit, practical experiences in the use of thermography to assist governmental officials in evaluating thermal efficiency in public buildings, and information on standards and training.

Treado, S. J. and D. M. Burch (1978) Evaluation of Hand.Held Infrared Thermometers for "R" Measurement. Center for Building Technology, National Bureau of Standards, 20 pages.

Hand-held infrared thermometers were not recommended for use in determining the thermal resistance $(R)$ values of walls. Under steady-state conditions, measurements of the R-value of an insulated wall showed an average error of more than $50 \%$. Under dynamic conditions, the error approximately doubled.

Some of the error in $\mathrm{R}$ determination using radiometers is due to inaccurate temperature measurement. However, even if the instruments were perfect in indicating surface temperatures, substantial error in $\mathrm{R}$ determination would occur due to other factors, such as uncertainty in the surface heat transfer coefficient and emissivity, and transients due to cyclic operation of the furnace and outdoor conditions.

The best application of the hand-held temperature indicators is as a qualitative measuring device. It should be possible to determine whether or not a wall is insulated or if voids or other insulation failures are present. Great care should be taken to ensure accurate calibration of the devices which require that procedure. Separate indoor and outdoor calibrations should result in increased accuracy. Care should be exercised to minimize uncertainties due to transients. For greatest accuracy, measurements should be made under conditions which produce a 20 to $30^{\circ} \mathrm{F}$ temperature difference across the wall, and the cold-side surface of the wall should be above $32^{\circ} \mathrm{F}$.

(reviewed in Marshall, Stephen J. Infrared Thermography of Buildings a Bibliography with Abstracts, 1979) 